\title{
El otro Centenario: visiones femeninas del Quijote en 1905
}

\author{
ISABEL NAVAS OCAÑA*
}

\begin{abstract}
Resumen
E1 III Centenario del Quijote en 1905 fue la efemérides que vino a canalizar las ansias de regeneración nacional tras el desastre del 98, pero lo que hasta ahora no se ha señalado, ni se le ha dado la importancia que merece, es que algunas escritoras españolas reinterpretaron en clave feminista los símbolos nacionales de esa regeneración, es decir, convirtieron a don Quijote y a Dulcinea en la divisa de sus reivindicaciones, se valieron de ellos para reclamar un cambio en la vida de las mujeres, para defender el acceso a la educación superior, y aprovecharon además la ocasión para tejer redes de mujeres eruditas y para ejercer el magisterio sobre otras mujeres, dando lugar a un centenario paralelo, a otro centenario, que se desarrolló en los márgenes del oficial y que, como tal, merece ser analizado.
\end{abstract}

Palabras clave: Miguel de Cervantes; Don Quijote; III Centenario; escritoras; feminismo.

Title: The Other Centenary: Women's Visions of Don Quixote in 1905

\begin{abstract}
The III Centenary of Don Quixote in 1905 was the ephemeris that came to channel the desire for national regeneration following the disaster of ' 98 , but what has not been pointed out so far, nor has it been given the importance it deserves, is that some Spanish women writers reinterpreted in a feminist key the national symbols of that regeneration, that is, they used Don Quixote and Dulcinea as tools for their claims, demanding a change in the lives of women, and defending their inclusion into higher education. Likewise, they took the opportunity to weave networks of scholarly women and to instruct other women, giving rise to a parallel centenary, to another centenary, which was developed on the margins of the official and, as such, deserves to be analysed.
\end{abstract}

Keywords: Miguel de Cervantes; Don Quixote; III Centenary; Women Writers; Feminism.

* Universidad de Almería. minavas@ual.es / ORCID iD: https://orcid.org/0000-0003-2599-0445. 


\section{Cómo citar este artículo / Citation}

Navas Ocaña, Isabel. 2020. «El otro Centenario: visiones femeninas del Quijote en 1905». Anales Cervantinos 52: 87-118, https://doi.org/10.3989/anacervantinos.2020.004.

\section{INTRODUCCIÓN}

La celebración del III Centenario de la publicación del Quijote en 1905 estuvo profundamente condicionada por la terrible crisis en que España se sumió tras la pérdida de las últimas colonias. Se quiso, por ello, hacer de la efemérides cervantina el emblema de la regeneración del país y se debatió profusamente sobre el idealismo de Cervantes, sobre su condición de hombre de acción, sobre el quijotismo que las nuevas generaciones debían emular para salir del marasmo, etc. Al hilo de estas reflexiones, y dada la expansión del feminismo y las conquistas de las mujeres a lo largo del siglo XIX, muchos cervantistas se interrogaron también sobre la responsabilidad de las españolas en la decadencia de la nación y sobre el papel que podían desempeñar en su futura regeneración, concluyendo en la mayoría de los casos que su función debía limitarse a la de ángel del hogar, esposa y madre ${ }^{1}$.

Pero las mujeres habían ganado importantes batallas en la pasada centuria, y una de ellas, la más importante quizá, fue la de la educación. La creación de las Escuelas Normales de Maestras les otorgó la oportunidad de seguir estudios superiores, aunque no fueran todavía los mismos que cursaban los hombres, y de ejercer después una profesión honorable, y por supuesto las proveyó de una formación que las capacitaba para disertar sobre cualquier asunto de enjundia. El aniversario de la publicación del Quijote fue la ocasión, como veremos, para hacer pública exhibición de sus conocimientos y sobre todo para replantearse su situación en la sociedad y exigir un cambio, un cambio que no es exactamente el mismo que los cervantistas anhelan en este momento para la maltrecha España.

La Crónica del Centenario de Miguel Sawa y Pablo Becerra es el documento oficial de las celebraciones cervantinas y gracias a ella tenemos abundante información sobre la participación de las mujeres, aunque no toda la que hubiera sido deseable, como veremos. Pues bien, de acuerdo con los datos que proporciona la Crónica, las mujeres estuvieron presentes de manera notoria en los fastos organizados por distintas instituciones, entre las que destaca la Unión Ibero-Americana, que contó con la presencia de Emilia Pardo Bazán y Carmen de Burgos; hubo festejos además en las Escuelas Normales de Maestras de prácticamente todo el país; en la función del Teatro

1. He tratado ampliamente todas estas cuestiones en el artículo «En sus brazos se ahoga todo heroísmo. La crisis del 98 y los personajes femeninos del Quijote» (Navas Ocaña en prensa). 
Real de Madrid, uno de los últimos actos programados del Centenario, participaron actrices muy destacadas como la célebre María Guerrero; y la asistencia femenina es reseñable también en algunos juegos florales en honor de Cervantes, como los celebrados en Albacete o en Manila, aunque aquí las mujeres figuran simplemente como reinas de las fiestas y su voz no se deja oír. Tampoco se oyó, por supuesto, ni en la Real Academia Española, ni en la Universidad ni en el Ateneo, donde primaron otras, consideradas entonces mucho más autorizadas que las de las mujeres para hablar del Quijote, del libro español por excelencia ${ }^{2}$, voces como la de Juan Valera, encargado del discurso oficial para la sesión solemne de la Academia, las de Menéndez Pelayo y Ramón y Cajal en la Universidad Central, y la de Francisco Navarro Ledesma, presidente de la sección literaria del Ateneo. De los discursos de estos próceres dará cumplida cuenta la Crónica de Sawa y Becerra (Navas Ocaña en prensa). Pero las mujeres hablaron en otros foros y no lo hicieron siempre en consonancia con lo que estos ilustres cervantistas planteaban sobre el Quijote, dando lugar a una especie de centenario paralelo, otro, que se desarrolló en los márgenes del oficial y que, como tal, merece ser analizado 3 .

\section{MuJeres FLORERO, O NO TANTO...}

Sobre las reinas de los juegos florales poco podemos decir, salvo que se las obsequió con la consabida "corte de amor» y que un sinfín de galantes caballeros les dedicaron exaltados elogios a su belleza y a su capacidad de abnegación y sacrificio, como los ángeles del hogar que se pretendía que fueran. Juan Antonio Cavestany, académico de la Española, que ostentó el cargo de mantenedor de los juegos florales organizados por la Asociación de la Prensa de Albacete, dirige a la joven Valentina Cuervas y Mons de Quijano y a «su corte de amor» una encendida alocución que encaja en lo que se conoce como ideología de la domesticidad, y en ella define el papel que el ángel de hogar ha de desempeñar en la regeneración de España, un papel que consiste simple y llanamente en apoyar «la acción perseverante del hombre» (Navas Ocaña en prensa). Corte de amor también tuvo la reina de los juegos florales de Manila (Sawa y Becerra 1905, 556), y el festival del Círculo Católico de Pontevedra contó con una presidencia de honor formada por once

2. Clarín se refiere a él como la «Biblia profana española», para Galdós es «el más clásico y el más contemporáneo de todos los libros» y Ángel Ganivet lo considera «nuestra obra típica, la obra por antonomasia» (en García Sánchez 2005, 25, 16 y 141). Emilia Pardo Bazán comparte esta valoración del Quijote y sostiene, como sus contemporáneos, que en Cervantes y en el Quijote «se encierra la esencia de nuestra nacionalidad, nuestra psicología colectiva» (1905b, 266), que se trata de «la magna tradición clásica nacional, identificada con el espíritu de la patria» (1905c, 330).

3. Aunque las contribuciones femeninas al III Centenario han sido objeto de estudio en los últimos años (Castells 2016; Martín Murillo y Fraga 2016), la perspectiva que adoptamos huye de lo puramente descriptivo y pretende explicar en su conjunto lo que significó para las mujeres ilustradas de la época su participación en las celebraciones cervantinas. 
jóvenes ataviadas con mantilla blanca de encaje, como muestra la instantánea incluida en la Crónica $(1905,499)$.

En Zaragoza, en cambio, la presidencia honorífica la ocupó una aristócrata, la duquesa de Villahermosa, que fue la patrocinadora de las celebraciones y el Ayuntamiento la nombró como tal en agradecimiento por su generosa aportación económica (Sawa y Becerra 1905, 548). Que esta dama noble no debió de ser una simple «mujer florero», como las inertes soberanas de los juegos florales, lo prueban los parabienes que su posición y su fortuna le valen ante las autoridades zaragozanas encargadas de la celebración del Centenario. De hecho, la Crónica, que detalla con prolijidad cada una de las contribuciones monetarias de la duquesa a la efemérides cervantina, incluida la edición del Álbum cervantino aragonés, en el que se recogen «noticias y documentos relacionados con las fiestas del centenario» $(1905,549)$, no escatima en elogios hacia su persona: se refiere a ella como «admirable mujer», «noble descendiente de los reyes de Aragón», «reina de Aragón», «dama insigne», «honor de España» (1905, 548-549). Pero lo más importante, lo que, en mi opinión, debe ser subrayado, es que una mujer tan notable como doña Emilia Pardo Bazán quisiera ver en las fiestas que la duquesa organizó en el castillo de Pedrola un Centenario distinto, un Centenario diferente al oficial, al que se había pergeñado en Madrid desde instancias gubernamentales. En sus crónicas de La Ilustración Artística, Pardo Bazán, que se va a mostrar, como veremos enseguida, muy crítica con el programa oficial, elogia los esfuerzos de la duquesa, a quien relaciona con la célebre duquesa del Quijote ${ }^{4}$, y llega incluso a recomendar a los cervantistas extranjeros que acudan a las celebraciones zaragozanas auspiciadas por esta dama antes que a las planeadas en Madrid:

La duquesa de Villahermosa no es de las que se quedan a medio camino. [...] díganlo ahora mismo las fiestas con que va a solemnizar el Centenario del Quijote en su castillo de Pedrola, donde se supone que situó Cervantes lo narrado en los capítulos del XXX al LXII, desde el encuentro con la bella cazadora, que era una duquesa de Villahermosa, con los episodios de la dueña Dolorida, encanto de Altisidora, la Trifaldi, el envío de Sancho a la Barataria, el espanto cencerril y saturno, y demás "zarandajas". Seguramente estas fiestas cerca de Zaragoza serán tan señoriales y bien organizadas, como amenazan las de Madrid ser insípidas y hasta sin relación con lo que pretenden conmemorar. Si yo fuese extranjero curioso y cervantista, huiría del Centenario de Madrid y buscaría a Cervantes en el castillo de los duques (Pardo Bazán 1905a, 170).

En definitiva, no todas las reinas y presidentas de honor del Centenario debieron de ser ni tan silentes, ni tan contemplativas, como las pinta la Cró-

4. Sobre la posible identidad de la duquesa del Quijote ya se había pronunciado José Antonio Pellicer en su edición del Quijote, decantándose por doña María de Aragón, séptima duquesa de Villahermosa, antepasada de la que ahora nombra doña Emilia (Pellicer 1798-1800, 164; Navas Ocaña 2008, 164). 
nica. La duquesa de Villahermosa es una prueba de ello y doña Emilia no desaprovecha la ocasión que esta dama pudiente y linajuda le brinda para subrayarlo, para mostrar a una mujer en una posición de poder, una mujer ante la que se inclinan los políticos del momento, y sobre todo para demostrar que las mujeres, a poco que dispongan de los medios económicos necesarios, harían las cosas de otro modo y festejarían a Cervantes de manera bien distinta. Todo esto dice el texto de Pardo Bazán, en mi opinión, sin decirlo abiertamente. Se van sentando así las bases de lo que va a ser ese otro Centenario cervantino auspiciado por las mujeres, que va a tener en doña Emilia a una de sus principales valedoras.

En cuanto a las actrices, destaca al respecto la información sobre la función celebrada en el Teatro Real de Madrid en mayo de 1905, que se anuncia como «el último festejo oficial del centenario» (Sawa y Becerra 1905, 114). En ella se estrenaron el entremés de Cervantes Los dos habladores, así como La primera salida de Sellés, La aventura de los galeotes de los hermanos Álvarez Quintero y El caballero de los espejos de Ramos Carrión, obras inspiradas en distintos capítulos del Quijote (114). El elenco de participantes es fundamentalmente masculino. De hecho, La aventura de los galeotes y El caballero de los espejos carecen de personajes femeninos, pero en Los dos habladores y en La primera salida sí actuaron mujeres, en concreto la insigne María Guerrero. La Crónica valoró muy positivamente su actuación y la de la Sra. Cancio en el papel de mozas de partido ${ }^{5}$ y dejó constancia de que en la apoteosis final en honor de Cervantes, apoteosis que consistió en una representación del templo de la Fama en torno al busto del alcalaíno modelado por Benlliure, María Guerrero encarnó nada menos que a España y se colocó «al frente» de «los hombres que más brillaron en los siglos XVII, XVIII y XIX», como Lope, Tirso, Calderón, Quevedo, Jovellanos, Moratín, Goya, Espronceda, el duque de Rivas, etc. $(1905,115)$.

La representación del Real, que gozó de la presencia del Rey, fue muy elogiada en la Crónica y sus responsables recibieron toda suerte de parabienes, lo que incluía también a las mujeres, a las que se obsequia con el galante trato de señoras y señoritas ${ }^{6}$, y cuyos méritos actorales se ponderan. No contaron sin embargo con tantos papeles de relevancia como los hombres en esta solemne función, no hubo ni una sola mujer célebre en ese templo de la fama repleto de hombres ilustres, pero al menos, encabezando la comitiva masculina, aparece la figura de la gran María Guerrero y lo hace en el papel más honorable de todos, el de España. Todo esto tiene en mi opinión un importante valor simbólico que debe ser subrayado, máxime cuando la profesión de actriz es una de las pocas ocupaciones reconocidas en este momento para

5. «Con discreción han rematado esta peligrosa aventura los artistas del teatro Español. [...] retozonas y desenvueltas en las dos mozas de partido, la Guerrero y la Cancio» $(1905,115)$.

6. La crónica se refiere a ellas como Sra. Guerrero, Sra. Cancio, Srta. Gómez y Srta. Suárez $(1905,114)$. 
las mujeres, y aunque siga habiendo en su contra muchos prejuicios ${ }^{7}$, las alabanzas de la Crónica a la actuación de María Guerrero contribuirían evidentemente a prestigiarla y por ende vendrían a sancionar positivamente la presencia de las mujeres en la escena cultural, en la esfera pública.

\section{UNA CANTERA DE MUJERES CERVANTISTAS: LAS EsCUELAS Normales DE MAestras}

Otra profesión aceptada por la sociedad de la época es la de maestra. Gracias a la Ley Moyano, promulgada en 1857, se crearon las Escuelas Normales de Maestras, que jugarán un papel fundamental en el fomento y desarrollo de la educación femenina (Scanlon 1987, 194) y serán la mayor «cantera de militancia del inicial movimiento de mujeres» (Ballarín 1996, 87) ${ }^{8}$. Pues bien, para el año 1905 estos establecimientos llevan ya medio siglo funcionando y el III Centenario del Quijote les brindará una magnífica oportunidad de demostrar el grado de instrucción que han alcanzado tanto las docentes como las jóvenes discípulas, algunas de ellas autoras de notables estudios sobre el Quijote que les valen, sin lugar a dudas, la condición de cervantistas.

La Crónica dará fe de las celebraciones que tuvieron lugar en las Escuelas Normales de Maestras de buena parte del país, aunque no llegará a reproducir ninguno de los numerosos discursos pronunciados por las profesoras, salvo el de María Mosteyrin, de la Normal de Oviedo, ni ninguno de los trabajos que sobre Cervantes y el Quijote leyeron las alumnas. Se limita a ofrecer información sucinta de lo acaecido en cada una de ellas y a ilustrarla con las fotos de las directoras o con algunas instantáneas de grupo, como en el caso de Lérida (Sawa y Becerra 1905, 278, 337, 373, 445, 453, 480, 528 y 547).

Las alumnas de la Normal Central de Madrid representaron el entremés La guarda cuidadosa y entonaron un "Canto a Altisidora». Además, algunas de ellas leyeron trabajos académicos sobre Cervantes (Sawa y Becerra 1905, 278-279). Destaca al respecto María del Rosario Garrido, discípula de Concepción Sáiz Otero ${ }^{9}$, cuyo análisis de los «Libros de caballería» fue publica-

7. Valgan como muestra las palabras de Navarro Ledesma en la primera de las conferencias que impartió en el Ateneo. Allí, al hablar de las compañías de cómicos del tiempo de Cervantes, se refiere a las actrices que formaban parte de ellas como «marimachos» y no duda en poner en solfa su moralidad (1905, 216).

8. Así lo señalaba ya en 1902 Concepción Sáiz Otero en el artículo «El feminismo en España», que se publicó en el n. ${ }^{\circ} 13$ de La Escuela Moderna: «Excepción hecha de los valiosos trabajos de Concepción Arenal y de la "Biblioteca de la Mujer", iniciada por la señora Pardo Bazán, el movimiento feminista no ha encontrado en nuestra patria otras defensoras que las maestras e institutrices» (1902, 89).

9. «Concepción Sáiz Otero fue profesora de la Escuela graduada de niñas creada por la Asociación para la Enseñanza de la Mujer, en la que ocupó también la cátedra de Pedagogía, además de profesora de la Normal de Maestras de Madrid y de la Escuela de Estudios Superiores de Magisterio 
do luego en el n. ${ }^{\circ} 170$ de la revista La Escuela Moderna. Al acto acudieron el rector de la Universidad, un representante del ministro de Instrucción pública y varios senadores, lo que parece indicar que se le quiso dar un carácter protocolario y oficial, y se recurrió para ello a algunos prohombres, cuyo papel no fue otro que el de respaldar, el de sancionar positivamente, la pública manifestación de la sabiduría femenina que la Escuela hizo con motivo del Centenario.

Pero hubo algunas Escuelas de Maestras que organizaron la conmemoración conjuntamente con otros centros educativos. Así sucede con la Normal de Alicante, que tuvo un cierto protagonismo en el acto celebrado en el palacio municipal el 8 de mayo, ya que la profesora de Música, Srta. Miquel, se encargó de amenizar la velada «ejecutando al piano de modo magistral varias sonatas clásicas de autores del siglo XVII»; y la profesora Regina Pérez Alemán ${ }^{10}$ recogió el diploma obtenido en el certamen literario convocado por la propia Normal (Sawa y Becerra 1905, 332). Sin embargo, los oradores que disertaron sobre el Quijote fueron todos hombres, la mayoría catedráticos. El programa de la fiesta organizada por las Escuelas Normales de Burgos contó, en cambio, con un discurso de apertura de la directora Julia Alegría Corral de Sarmiento y otros tres a cargo de profesoras: «Estudio biográfico de Cervantes» de Crescencia López Revuelta, «Aspecto educativo del Quijote» de B. Encarnación García García y «Estudio geográfico de los lugares donde se desarrolló la acción del Quijote») de Antonieta Freixa Torroja ${ }^{11}$ (Sawa y Becerra 1905, 372-373). Lo mismo sucede con la Normal de Granada, donde Pilar Jiménez pronunció la conferencia «Cervantes y el Quijotismo» (Sawa y Becerra 1905, 435), que editaría luego la granadina Tipografía de López Guevara. En Málaga, el acto conmemorativo corrió a cargo tanto de la Normal de Maestras como del Instituto General y Técnico, y consistió en la representación teatral del capítulo LXIX del Quijote y en la coronación de un busto de Cervantes «amenizada por un diálogo en verso», obra de Suceso Luengo, la directora de la Normal $^{12}$. Hubo además un festival infantil en el teatro Vital Aza que concluyó con un coro de niños y niñas entonando el himno a Cervantes, compuesto también por Suceso Luengo (Sawa y Becerra 1905,

(donde ocupó la cátedra de Lengua), y una de las primeras psicólogas españolas» (Ezama Gil 2015, 12).

10. Regina Pérez Alemán fue una precursora de la utilización del cine con fines didácticos (Camarero Rioja 2013). Natividad Ortiz Alvear la incluye en Mujeres masonas en España. Diccionario biográfico (1868-1939) (2007, 311). Ver también Teresa Marín Eced (1990, 384).

11. Antonieta Freixa desarrolló una amplia carrera docente que se inicia en 1901 en la Normal de Guadalajara y continúa en 1903, primero en Badajoz y luego ya en Burgos. Fue también profesora en las Normales de Toledo, Tarragona, Valencia, Barcelona y Gerona. En 1928, la Junta de Ampliación de Estudios (JAE) le concedió una ayuda «para ir a Italia a estudiar la reforma de las escuelas primarias y la renovación pedagógica que en ese país se había realizado con el programa de "Escuelas Nuevas"» (Santos Vaquero 2012, 205-207).

12. La zamorana Suceso Luengo fue directora de las Normales de Soria, La Habana y Málaga Gran admiradora de Concepción Arenal y de Emilia Pardo Bazán, defendió siempre, como ellas, el derecho de la mujer a la educación (Badillo Baena 1992). 
473). Carmen García de Castro fue una de las premiadas en el certamen artístico y literario convocado para la ocasión por el trabajo «El Quijote en la escuela», que dedica precisamente a Suceso Luengo, su maestra, como «homenaje de admiración y cariño», y que se editaría en Écija, en la Imprenta Reyes, Mas y Prat, ya en $1906^{13}$.

Obsérvese cómo la temática de los discursos gira fundamentalmente en torno a dos asuntos: la biografía de Cervantes y los valores educativos del Quijote. De hecho, en San Sebastián, además de leer varios sonetos en honor a Cervantes y algunos fragmentos del Quijote, una de las alumnas, Patrocinio Amenábar, disertó sobre la «Biografía de Cervantes» (Sawa y Becerra 1905, 445). Y lo mismo sucedería en Lérida, donde Genoveva Aixalá habló también sobre la vida del alcalaíno, y Josefa Forcadell, sobre un episodio concreto: la batalla de Lepanto ${ }^{14}$. Por otra parte, en Lérida, dos de las conferencias versaron sobre aspectos gramaticales del Quijote y se leyó la carta de Teresa Panza a la duquesa como muestra del género epistolar ${ }^{15}$, un género que interesó mucho también a las oradoras de la Normal de Huesca, en concreto a Jacoba Pérez y a Araceli Egaralar ${ }^{16}$. Hubo además en Huesca quien disertó sobre el Quijote de Avellaneda ${ }^{17}$ y no faltaron tampoco ni las aproximaciones a la biografía de Cervantes ${ }^{18}$ ni las representaciones teatrales, que, como en el caso de Málaga, consistieron en una versión teatralizada de lo acontecido a don Quijote y a Sancho en el palacio de los duques (Sawa y Becerra 1905, 447). En Zamora, la directora de la Normal, Carmen Tapia, fue la encargada de poner en antecedentes a su auditorio sobre la vida de Cervantes y hubo además «un erudito discurso de la profesora doña Vicenta Burón, titulado Utilidad moral y filantrópica del Quijote (Sawa y Becerra 1905, 548).

En cuanto a la Escuela de Institutrices de Barcelona, la conmemoración del Centenario consistió en la lectura de trabajos académicos, algunos también

13. Carmen García de Castro nació en Sorbas (Almería) en 1886 y estudió Magisterio en la Normal de Málaga, donde fue discípula de Suceso Luego y de Aurora Larrea, maestras feministas e institucionistas, que influyeron mucho en ella, y se trasladó después a la Escuela de Estudios Superiores de Magisterio de Madrid. Comienza su vida profesional como docente en 1913 en la Normal de Cádiz, la continúa en 1914 en Albacete, para ocupar finalmente en 1922 la cátedra de Valencia que María Carbonell deja vacante por jubilación en esta fecha (Agulló Díaz 2001, 472). De ideas institucionistas, defensora de los derechos de las mujeres y miembro de FETE, fue sometida a expediente de depuración tanto durante la dictadura de Primo de Rivera en 1929 (Agulló Díaz 2001), como tras la guerra civil, con el franquismo (Agulló Díaz y Fernández Soria 2014, 212 y 215-216).

14. «Biografía de Cervantes» y «Batalla de Lepanto en la que se distinguió Miguel de Cervantes» son respectivamente los títulos de las ponencias de Aixalá y Forcadell (Sawa y Becerra 1905, 450).

15. Se trata de «Análisis gramatical sobre un trozo en prosa del Quijote» de Teresa Cortada y «Análisis gramatical sobre un trozo en verso del Quijote» de Encarnación Llairó. La señorita Angela Baró fue la encargada de leer la carta de Teresa Panza a la duquesa (Sawa y Becerra 1905, 450).

16. «Estudio de la carta de la Duquesa y Teresa Panza y su contestación» de Jacoba Pérez; «Estudio de la carta de Sancho Panza a su mujer Teresa Panza, y la contestación de esta» de Araceli Egaralar (Sawa y Becerra 1905, 447-448).

17. «Juicio crítico que de la obra de Avellaneda hace Cervantes» de Josefa Jiménez (Sawa y Becerra 1905, 447).

18. «Cervantes es nuestro» de Julia Zasaosa (Sawa y Becerra 1905, 448). 
de carácter biográfico ${ }^{19}$, entre los que debió de destacar el de María Baldó Massanet, titulado «Notas sobre las mujeres del Quijote», dado el comentario que sobre él incluye la Crónica: «La conferencia de la señorita María Baldó fue verdaderamente notable, y en ella hizo un estudio atinadísimo de las mujeres -algunas de psicología tan extraña- que figuran en el Quijote» (1905, $369)^{20}$.

Estas «Notas sobre las mujeres del Quijote» de la joven María Baldó, luego conocida pedagoga y escritora albaceteña afincada en Cataluña, que llegó a ser Presidenta del Lyceum Club de Barcelona (Palau 2012, 21-24), se unen al discurso de apertura pronunciado por María Carbonell en la Normal de Maestras de Valencia, que con una temática y un título similar al de Baldó, «Las mujeres del Quijote», afortunadamente sí se publicó, aunque no en la Crónica ${ }^{21}$ sino de manera independiente en la Imprenta valenciana de Doménech y Taroncher en $1905^{22}$. Las alumnas valencianas leyeron también un número importante de trabajos académicos que versaron sobre cuestiones de estilo («figuras de construcción y elegancias de lenguaje» en el Quijote), valores educativos de la obra cervantina («preceptos aplicables a la educación») y sobre los personajes femeninos («La mujer ideal de don Quijote. Semblanza de Dulcinea») (Sawa y Becerra 1905, 527).

Por tanto, estas primeras cervantistas que salen de las Escuelas Normales de Maestras muestran un interés particular por la biografía de Cervantes, por algunos aspectos lingüísticos de su obra, por su utilidad didáctica y por las mujeres que pueblan las páginas del Quijote. Aunque la mayoría de sus discursos y trabajos académicos no han llegado hasta nosotros porque no se publicaron, los que sí lo hicieron responden en mayor o menor medida a estas líneas temáticas. Enseguida los analizaremos.

La Crónica incluyó además información sobre dos mujeres poetas que tuvieron una participación notable en las celebraciones cervantinas de Cádiz y Sevilla. Me refiero a Carmen Eulate ${ }^{23}$, a quien Sawa y Becerra reputan como «distinguida poetisa, autora del soneto “A Cervantes"» $(1905,388)$, leído en

19. A cargo de las profesoras Josefa Brichs («Quién era Cervantes») y Antonia Grau («Algo acerca de la vida literaria de Cervantes»).

20. Desafortunadamente no se debió publicar y por tanto no hay forma de tener más noticia sobre él que la de su título. Así lo corrobora Montserrat Bacardí, estudiosa de la obra de Baldó (2006, 7).

21. La Crónica se limita a mencionar el discurso de María y a incluir una foto suya $(1905,528)$.

22. Hay edición contemporánea publicada por el Instituto Alfonso el Magnánimo de Valencia en 2006 bajo la supervisión de Begoña Sáez Martínez.

23. Se trata de Carmen o Carmela Eulate Sanjurjo, como se la nombra en el pie de foto que la Crónica incluye de ella $(1905,388)$. Eulate nació en Puerto Rico, donde estaba destinado su padre, el almirante español Antonio Eulate, pero la familia regresa a España en 1898 y se instala primero en Canarias y más tarde definitivamente en Barcelona. Carmen desarrolló allí una carrera literaria larga y meritoria. Cultivó la narrativa, la poesía, el periodismo, la traducción, la biografía y el ensayo. Su novela La muñeca (1895) ha sido muy apreciada por la crítica (Rivera 1999; Grau-Llevería 2004). Particular relevancia adquieren en mi opinión sus ensayos feministas: La mujer en la historia (1915), La mujer en el arte: Inspiradoras (1915), La mujer en el arte: Creadoras (1917), La mujer moderna (1924) (Morales Zeno 1995). 
el Ateneo de San Fernando, en Cádiz. Y otro tanto puede decirse de Mercedes de Velilla ${ }^{24}$, calificada igualmente como «distinguida poetisa sevillana» y participante en la coronación del busto de Cervantes que tuvo lugar en el teatro San Fernando de Sevilla (1905, 509 y 517).

Por lo demás, la Crónica dio cuenta de los muchos premios que se convocaron para honrar la memoria de Cervantes. Como es previsible, los ganadores son en su mayoría hombres, pero hay algunas excepciones. Por ejemplo, el Instituto General y Técnico de Baleares anunció un certamen para premiar el mejor estudio crítico de la novela Rinconete y Cortadillo, que gana María Pons y Monedero, «acompañada al escenario del brazo del señor Alcocer» $(1905,353)$-los cronistas no pueden evitar el tono paternalista, de trasnochada galantería, para referirse a la joven-. El certamen artístico y literario del Instituto General y Técnico de Málaga cuenta con dieciocho premiados, de los cuales tres son mujeres: Carmen García de Castro, a quien ya hemos mencionado, Antonia Ramos Fernández y Elena Cortés Leiva (1905, 474). Y otro tanto sucede en el concurso de la Escuela Superior de Artes Industriales de Córdoba, con diecinueve premiados, entre los que hay dos mujeres: Dolores Madueño y Elisa Guerra $(1905,402)$.

En definitiva, la Crónica abunda en ejemplos de reinas de juegos florales, presidentas honoríficas y hermosas jóvenes ataviadas con mantilla, cuya presencia es un simple adorno, una mera cuestión decorativa. No obstante, muestra ya también a las mujeres ilustradas españolas de la época atreviéndose a ejercer como tales, ya sea en el noble papel de conferenciantes, o bien como lectoras de poemas que ellas mismas han compuesto, e incluso aparecen como ganadoras de certámenes artísticos y literarios en los que compiten con hombres, lo que resulta aún más novedoso, y hasta se alaba la profesionalidad de algunas afamadas actrices como María Guerrero. Es cierto que la presencia femenina sigue siendo en número palmariamente inferior a la de los varones, pero, aprovechando el espacio que la legislación les brinda gracias a la creación de las Escuelas Normales de Maestras, las mujeres desarrollan una considerable actividad en torno a los fastos del centenario, una actividad de la que la Crónica se limitó a dejar constancia, sin incluir entre sus páginas desafortunadamente más que la breve intervención de María Mosteyrin. Esto evidencia, por supuesto, la escasa relevancia que se le concede todavía a lo que las mujeres pudieran opinar sobre Cervantes y sobre el Quijote, y en general sobre cualquier asunto relacionado con la cultura, frente a las autorizadas opiniones de algunos próceres de la escena intelectual del momento como Menéndez Pelayo, Valera, Ramón y Cajal, Navarro Ledesma, etc. Ahora bien, su presencia en la Crónica, por más que sea escasa, no deja de ser un signo de que los tiempos están cambiando para las mujeres y de que van a cambiar además considerablemente, y para bien, en los próximos años.

24. Su poesía completa ha sido editada recientemente por Renacimiento (Velilla 2018) y hay también edición contemporánea de su obra teatral más conocida, estrenada en 1876: El vencedor de si mismo (Velilla 2008). 


\section{DoÑa Emilia, LA GRAN AUSENTE}

Si dejamos a un lado las Escuelas Normales de Maestras, espacios concebidos como eminentemente femeninos, y prescindimos también de las actrices del Teatro Real y de las silentes reinas de los juegos florales, que desempeñaron papeles aceptados, o más o menos tolerados, por la moral tradicional del momento -ya hemos hablado de los prejuicios contra las cómicas-, es la fiesta de la Unión Ibero-Americana, celebrada el 15 de mayo en el Paraninfo de la Universidad Central, la única con repercusión pública amplia y sin sesgo de género ${ }^{25}$ en la que las mujeres intervinieron en pie de igualdad con los hombres, haciendo gala de su recién estrenada condición de eruditas, de cervantistas, y en ella expresaron de manera decidida tanto su visión del Quijote como su disconformidad con la manera en la que las autoridades habían encarado la organización del Centenario.

La fiesta contó con numerosos representantes políticos de Hispanoamérica, a los que se unieron algunos senadores y diputados españoles, así como relevantes figuras de la aristocracia, el periodismo y la cultura de la época (Sawa y Becerra 1905, 275). Se leyeron poemas dedicados a Cervantes y hubo varios discursos, entre los cuales destacaron como los más aplaudidos, según se indica en una reseña de $L a$ Época ${ }^{26}$, los de dos mujeres: Emilia Pardo Bazán, una escritora ya consagrada, y Carmen de Burgos, que por entonces se estaba abriendo camino en el difícil mundo del periodismo y que acababa de protagonizar una sonada campaña a favor del divorcio en el Diario Universal, donde ejercía como redactora -sería la primera mujer en ocupar semejante puesto en nuestro país-, teniendo a su cargo la columna diaria «Lecturas para la mujer» (Nuñez Rey 2005, 117).

Pues bien, la Crónica del Centenario de Sawa y Becerra recoge, como muestra de lo acaecido en la velada de la Unión Ibero-Americana, solo la conferencia de Carmen de Burgos, que es además muy corta ${ }^{27}$. Llama la atención el considerable espacio que se le concede a Menéndez Pelayo, Valera, Ramón y Cajal, Navarro Ledesma y otros doctos varones del momento, cuyos extensos discursos -algunos sobrepasan largamente las diez páginasson reproducidos al completo, frente a las brevísimas colaboraciones femeninas, ninguna de las cuales excede las dos páginas, como sucede con el discurso de Carmen de Burgos, con el de María Mosteyrin Morales en la

25. Ya vimos que la celebración de la Normal Central de Madrid, por las autoridades que acudieron (el rector de la Universidad Central, un representante ministerial, algunos senadores, etc.), debió de tener cierta repercusión, pero no deja de ser una fiesta organizada por mujeres y para mujeres. No sucede lo mismo con la de la Unión Ibero-Americana.

26. La noticia, muy breve, se publicó sin firma con el título de «En honor de Cervantes» en la página 5 del n. ${ }^{\circ} 19.716$, correspondiente al 15 de mayo de 1905 . Allí se indica que los discursos de Pardo Bazán y Carmen de Burgos «produjeron verdadero entusiasmo».

27. He barajado la posibilidad de que no estuviera completa, de que se tratara de un extracto, pero he hallado la misma versión en la revista Unión Ibero-Americana, en un número extraordinario que da cuenta del festejo, publicado el 16 de junio (Burgos 1905, 62). 
Escuela Normal de Maestras de Oviedo y con el artículo «Don Quijote en Alemania» de Paz de Borbón, del que solo se publica un extracto. Las de Carmen de Burgos, María Mosteyrin y Paz de Borbón son, de hecho, las únicas contribuciones femeninas incluidas en la Crónica de Sawa y Becerra. Desafortunadamente, los textos que muchas maestras escribieron para conmemorar el centenario brillan por su ausencia, pero quizás la más llamativa de todas sea la omisión del discurso de doña Emilia Pardo Bazán en la Unión Ibero-Americana ${ }^{28}$, que pudo estar motivada por el desacuerdo que la escritora gallega había mostrado públicamente con la forma en la que se estaban organizando los actos conmemorativos del III Centenario.

Pardo Bazán se refirió a esta cuestión en la columna «La vida contemporánea», que publicaba La Ilustración Artística de Barcelona, concretamente en los números 1217 y 1221, correspondientes al 24 de abril y al 22 de mayo de 1905. Allí tilda de «pobre», «mezquino», «inadecuado» y «triste» el programa oficial del centenario, se mofa de algunos curiosos eventos, como la batalla de las flores, que poco tienen que ver con Cervantes, y se queja de que todo se haya hecho «a última hora, atropelladamente» (1905b, 266), por el característico «método nuestro de proceder por sorpresas y chispazos», con tanta «precipitación» que de su intervención en la velada de la Unión IberoAmericana apenas le han avisado con dos días de antelación (1905c, 330). Lo cierto es que doña Emilia parece bastante disgustada con el cariz que ha tenido la celebración oficial y no duda en manifestarlo a las claras con una contundente declaración que haría enrojecer a más de un político de la época, a poco que tuviera una pizca de dignidad y de amor patrio: «Para festejar así al Quijote, más valiera no festejarle» $(1905 \mathrm{~b}, 266)$.

No dice nada, sin embargo, doña Emilia sobre la insignificante participación de las mujeres en los fastos del Centenario, no hay ningún reproche, ninguna queja al respecto, pero me atrevo a aventurar que esa disconformidad, esa alusión a «los personalismos egoístas y absorbentes» (1905b, 266), tan propios de los políticos y los intelectuales de su tiempo, con los que ella ha tenido que lidiar en muchas ocasiones -la más sonora de todas, el rechazo de su candidatura a la Real Academia-, esa discrepancia profunda que destilan sus palabras, quizás tiene que ver con su propia exclusión del núcleo rector del Centenario, exclusión que probablemente vio como una injusticia, dados sus muchos méritos, y que le haría pensar indefectiblemente, aunque no lo dijera, que de nuevo la causa era el hecho de ser mujer ${ }^{29}$.

28. De doña Emilia la Crónica solo incluye una noticia de carácter frívolo: la asistencia a la fiesta del marqués de Cerralbo, vestida con «un traje de color heliotropo» (Sawa y Becerra 1905, 117).

29. No obstante, en la columna sobre «La vida contemporánea», publicada en La Ilustración Artística el 22 de mayo, Pardo Bazán reproduce el discurso que pronunció en la Unión Ibero-Americana, «ampliado en su parte inicial y con algunas modificaciones de estilo» (Ezama Gil 2013, 134), y de ahí toma la revista Unión-Iberoamericana algunos fragmentos y los publica a su vez en el número extra del 16 de junio (Pardo Bazán 1905d). El discurso de la escritora gallega versó fundamentalmente sobre el carácter aglutinador de la lengua castellana, el único lazo que, a su juicio, «mantiene nuestra unión moral con las naciones del Nuevo Continente» (1905d, 63). 


\title{
5. Resucitar a don QuiJote Para Que unA nueva Dulcinea Viva
}

La conferencia de Carmen de Burgos en la Unión Ibero-Americana, titulada «La resurrección de don Quijote», participa también de la unánime preocupación por España y de las ansias de regeneración que van a ser una constante en los textos del III Centenario. De hecho, enlaza con la conferencia que pronunció días antes en el Ateneo Francisco Navarro Ledesma, a quien la almeriense menciona nada más comenzar. Desde la tribuna del Ateneo, Navarro Ledesma también había preconizado la resurrección de don Quijote, en su caso como símbolo del surgimiento de una nueva España ${ }^{30}$, y a esta circunstancia alude precisamente Carmen de Burgos, poniendo un énfasis especial en los ideales de libertad, progreso, justicia y cultura que serían, en su opinión, los pilares sobre los que se habría de asentar el renacer, la renovación, la transformación de la sociedad española:

\begin{abstract}
Se lo oí decir a Navarro Ledesma en el Ateneo, y su acento convencido llegaba hasta el fondo de mi corazón, escuchando aquella parábola hermosa en que nuestro redentor don Quijote se alzaba de su sepulcro al tercer aniversario secular, y derribando la losa de nuestras rutinas, enlazaba a la amante Dulcinea en un abrazo fecundo, engendrador de ideas, de nuevos derroteros, manantial de vida libre, de una sociedad donde brillen los ideales del progreso, de la justicia y del arte (Burgos 1905, 275).
\end{abstract}

Carmen de Burgos es muy consciente de que don Quijote es para muchos intelectuales españoles del momento la figura inspiradora, el héroe al que emular, el símbolo en el que apoyarse para perseguir cualquier ideal: «El ansia de ideal se acentúa, la rebeldía late en el alma de todos: poetas, pensadores y patriotas buscan por paladín, para acometer magnas empresas, al valeroso caballero de la Mancha» $(1905,275)$. Y un poco después insiste: «... su espíritu no cambia; él infunde su aliento en nosotros; al calor de sus idea-

30. De hecho, al principio de su intervención Navarro Ledesma había proclamado: «Hoy, por dicha, no venimos aquí a enaltecer a un muerto, sino a honrar a un vivo, más vivo que todos nosotros los que aquí estamos y que todos los demás que andan por ahí fuera: al ingenioso hidalgo don Quijote de la Mancha, que goza la vida eterna más apetecible, la del ideal que toma carne, la de la ficción que a la sangrienta realidad se impone. Envidiemos a don Quijote, veneremos su perdurable vivir y no vayamos a buscar a luengas tierras superhombres de trastrigo cuando tenemos al mayor de todos en casa...» $(1905,205)$.

Hubo con ocasión del Centenario algunas curiosas resurrecciones del Quijote, como la auspiciada por el Padre Valbuena, seudónimo de J. Burgas (Riera 2005, 227), que hará vivir a don Quijote y a Sancho «nuevas aventuras en medio de los avances tecnológicos del siglo incipiente y las convulsiones políticas del momento», llegando incluso a ser recibidos por cervantistas ilustres en «centros de interés público como el Ateneo y el Palacio Real» (López Navia 2005, 72). Precisamente en el capítulo V, titulado "Que trata de las mil y una zarandajas que en honor de don Quijote se hicieron y dijeron en el Ateneo de Madrid», Valbuena se hace eco de la presencia de Carmen de Burgos en las celebraciones con que el Ateneo conmemoró el centenario de 1905: «Próximos a la Biblioteca, hacían petit comité D. Mariano de Cavia, autor de la idea del Centenario a quien abrazó don Quijote al entrar, con profunda emoción, el pintor Casas, la señora Burgos de Seguí (Colombine) que asistía en representación del bello sexo y el escultor Benlliure que representaba todo lo contrario» (Valbuena 1905, 77). 
les engendró esta Unión Ibero-Americana, refugio de las esperanzas de engrandecimiento en política, en progreso y en arte» $(1905,275)$.

Pero Carmen de Burgos lleva inmediatamente el agua a su molino y reinterpreta la resurrección de don Quijote en clave feminista. De toda la sociedad, las mujeres son, lo afirma con rotundidad, las que están especialmente interesadas en la resurrección de don Quijote. Veamos por qué. Carmen de Burgos lo describe como «buen caballero, galante y respetuoso hidalgo defensor de doncellas y viudas, deshacedor de entuertos y paladín de la justicia» (1905, 275); y es precisamente por estas cualidades del hidalgo manchego por lo que Carmen de Burgos se atreve a proclamar que «Todas las mujeres soñamos con la resurrección de don Quijote, que nadie puede desear tanto como nosotras la vuelta del buen caballero» $(1905,275)$. Para que se aprecie en toda su dimensión la difícil situación en la que viven las mujeres españolas, la escritora almeriense expone los infortunios que padecen tanto por costumbres trasnochadas como por la existencia de leyes injustas que las discriminan:

¿Cómo no soñar con la resurrección bendita del caballero de la Mancha en un país donde la mujer no puede salir sola a la calle sin exponerse a impertinencias y groserías, donde se lucha con ella para arrebatarla un sitio o un asiento, donde las leyes no la protegen ni la sociedad la educa como debiera? $(1905,275)$.

Don Quijote, que sería para Carmen de Burgos el símbolo de lo que denomina la "galantería española», con su resurrección, traería sin lugar a dudas una mejora considerable en las condiciones de vida de las mujeres españolas, y así parece creerlo Carmen de Burgos cuando proclama:

Aquel don Alonso Quijano, respetuoso hasta con las mozas de partido, galante con todas las mujeres, pronto a reñir desigual batalla en obsequio de los seres débiles o a morir proclamando las excelencias de su Dulcinea, es el prototipo de la galantería española, ahogada casi con el sanchopancismo importado de países más utilitarios y menos espiritualistas $(1905,275)$.

Los papeles ideales de Dulcinea y don Quijote han de ser asumidos por los hombres y las mujeres españolas. Carmen de Burgos confía en que, si así sucede, la situación de las mujeres cambiará, y lo hará sobre todo porque los hombres se convertirán efectivamente en nuevos Quijotes: «Las llamas de nuestro sol idealizan cuanto iluminan; a su luz, toda mujer puede parecer una Dulcinea, si los hombres llevan en el pecho un corazón de Quijote...». Por eso, concluye con una especie de ruego, o de oración, que no es sino el deseo de todas las mujeres españolas, es decir, la resurrección de don Quijote:

Acabarán las fiestas del Centenario, enmudecerán los modernos ingenios que cantan al divino Cervantes, pero quedará repercutiendo, como un eco del sentimiento general de las mujeres españolas, esta postrer oración. ¡Quieran los dioses que resucite nuestro señor Don Quijote! $(1905,275)$. 
Carmen de Burgos pretende que don Quijote reviva con el único fin de que las mujeres respiren aires de libertad. La tan ansiada regeneración de la vida nacional por la que abogan muchos de los intelectuales que participaron en el Centenario, adquiere con Carmen de Burgos una concreción muy singular: es la vida de las mujeres, la situación de las mujeres, las aspiraciones de las mujeres, las que se verán favorecidas; es la regeneración de la sociedad española, sí, pero lo es sobre todo de una parte fundamental de esa sociedad: las mujeres. Esta circunstancia convierte el discurso de Carmen de Burgos en algo muy singular en el conjunto de los textos que se difundieron con ocasión del III Centenario del Quijote.

Sin embargo, después de oír esa queja sobre la situación de las mujeres a quienes ni la ley protege ni la sociedad educa, hay algo que desalienta un tanto porque todo parece quedar reducido a una cuestión de galantería, que es la principal cualidad que poseen don Quijote y el propio Cervantes, tal como no se cansarán de proclamar sus exegetas. No se detiene Carmen de Burgos a precisar en qué cambiaría la situación de la mujer española la resurrección del galante don Quijote, aunque da por hecho que, como el hidalgo ha defendido a doncellas y a viudas, ha mostrado respeto hasta por las mozas de partido y además profesa una adoración especial por Dulcinea, su resurrección crea toda una serie de esperanzadoras expectativas para la vida de las mujeres, convirtiendo a los hombres en Quijotes, es decir, en galantes caballeros, y a ellas en ideales Dulcineas.

Desde un feminismo moderado, desde la queja atemperada, Carmen de Burgos se atreve -muy débilmente, hemos de admitirlo- a alzar la voz contra la injusta situación que padece la mujer española, y puesto que don Quijote, a la altura de 1905, está convirtiéndose en la bandera de todas las causas, y en particular, en la bandera que enarbolan aquellos que reclaman la modernización del país, se convierte también, gracias a Carmen de Burgos, en la bandera izada desde un feminismo todavía embrionario para reclamar la transformación de la vida de las mujeres, para que la galantería de don Quijote y su defensa de doncellas, viudas y mozas de partido inspire otro tipo de relaciones entre hombres y mujeres. Es una reclamación tímida, no hay lugar a dudas, pero una reclamación al fin y al cabo, independientemente de que, tal como lo plantea Carmen, todo consista en encajar a unos y a otras en los prototipos ideales de la novela cervantina, del trasnochado paradigma caballeresco: el caballero galante y la dama idealizada.

\section{LOS ÁNGELES DEL HOGAR Y LA REGENERACIÓN DE ESPAÑA}

A pesar de lo amortiguada que está la reivindicación de derechos, la lectura que del Quijote hace Carmen de Burgos contrasta sobremanera con lo que al respecto plantean algunos intelectuales del momento, que no conciben otro modelo femenino que el del ángel del hogar ni otra ocupación para las 
mujeres que la de ser esposas y madres. Lo hemos visto en la alocución que Juan Antonio Cavestany dedica a la reina de los juegos florales de Albacete e igual sucede en la de Segundo Moreno Barcia, incluida en la Crónica (1905, 415-417), o en «Las mujeres del Quijote» de Félix Uñó, artículo publicado en la revista barcelonesa La Academia Calasancia. La idea está presente también en algunos discursos pronunciados en la fiesta de la Unión IberoAmericana, de los que serían testigos Emilia Pardo Bazán y Carmen de Burgos, como el de Luis Armiñán, titulado «En honor de Cervantes». Armiñán repasa todo lo que España ha aportado al continente americano: su cultura, su idioma, su religión, sus poetas, sus valerosos soldados, etc. Sin embargo, la contribución de las españolas a la magna empresa americana se limita, en palabras de Armiñán, a «la belleza de nuestras mujeres y la virtud de nuestras madres» $(1905,54)$.

Pues bien, el ángel del hogar planeará también sobre los discursos de las mujeres y habrá algunas intelectuales que lo asuman abiertamente. Es lo que sucede con María Mosteyrin Morales ${ }^{31}$, profesora de la Escuela Normal de Maestras de Oviedo y única participante femenina en el «festival literariomusical» celebrado el 8 de mayo en el teatro Campoamor para homenajear a Cervantes (Sawa y Becerra 1905, 489-490), un festival en el que, junto a ella, intervinieron otros trece ponentes, todos profesores y alumnos de distintos centros escolares ovetenses. Esto hace de la presencia de María Mosteyrin un acontecimiento singular, la convierte sin duda en una excepción, pero al mismo tiempo evidencia que las mujeres están empezando a aparecer, aunque sean todavía muy pocas, en los foros culturales como algo más que meras acompañantes de los hombres, como algo más que meras comparsas.

No obstante, el discurso de Mosteyrin, titulado «Cómo impresiona el Quijote (datos directos)», coincide plenamente con el de Cavestany en la función que ha de desempeñar la mujer española en la renovación del país, una función que la relega al hogar y a la subordinación del marido. Veamos cómo lo argumenta.

Mosteyrin empieza pintando un panorama desolador, habla de un presente «sin idealidad y sin entusiasmos», de una «crisis desastrosa de la humanidad»; y esta crisis es de tal calibre que tanto ella como sus alumnas «muéstranse pesarosas, casi unánimemente, de no haber nacido en una época en que los caballeros trataban a las mozas de los mesones como a grandes damas, y sí en tiempos tales en que las grandes damas son tratadas como mozas de un mesón» $(1905,494)$. Evidencia así, al igual que Carmen de Burgos, el descontento de las mujeres con su situación en la sociedad del momento, sin ser tampoco muy explícita al respecto, y por supuesto juega con lo que ya es un tópico: la caballerosidad de don Quijote ${ }^{32}$.

31. Poca información he hallado sobre María Mosteyrin, salvo la mención que de ella hace Carmen Fernández Rubio en su estudio sobre la Escuela Normal Masculina de Oviedo (1997, 128).

32. No faltaron en la Crónica del Centenario otras voces que, como Carmen de Burgos y María Mosteyrin, ensalzaron la caballerosidad de don Quijote, como Lorenzo Rodríguez y Francisco Morán 
El discurso de Mosteyrin vira a partir de aquí hacia la cuestión nacional. De hecho, después de declarar "Yo me aflijo sólo por España» y de pedir disculpas por ello alegando su condición de débil mujer ${ }^{33}$, confiesa con emoción la añoranza por los tiempos heroicos de la Reconquista: «iCuántas veces he soñado que se acerca el momento en que vais a reanudar la serie de vuestras legendarias hazañas, dando comienzo a una nueva reconquista!» (1905, 494). Esta tarea de reconquista es masculina. Mosteyrin no parece tener duda al respecto cuando emplea ese «vosotros» que la excluye a ella y a las de su mismo sexo de las acciones de guerra.

Ahora bien, Mosteyrin les otorga a las mujeres una tarea, a su juicio, también importante en la regeneración del país, una tarea que han de desarrollar desde su condición de ángeles del hogar, sin abandonar el ámbito de lo doméstico y que se circunscribe a la educación de los hijos en los valores patrios:

\begin{abstract}
Mas si para descabezar vigorosos y aguerridos africanos os bastasteis vosotros, para acabar con esa tropa enfermiza de enconados enemigos de la patria, cuyas repulsivas y grotescas figuras parecen destacarse de un cartel modernista, necesitáis el concurso de la mujer buena, creyente y bien educada. [...] ellas pueden y deben contribuir por modo poderoso a labrar en el sagrado de la familia un lugar de refugio donde España reciba culto de profunda veneración, de amor inextinguible. [...] Así, pues, señores, yo abrigo la bien fundada esperanza de que vuestras hijas podrán decir un día ante el tribunal de Dios y de la patria: "de los que me entregasteis, ni uno solo se ha perdido"» $(1905,494)$.
\end{abstract}

María sale al paso incluso de quienes puedan pensar que la flaqueza innata de la mujer impedirá que lleven a buen puerto este alto cometido. Invoca entonces la unión de las mujeres, la hermandad femenina, en la que radica su fuerza: «Pero me diréis, tus discípulas son pocas y débiles para tan alta empresa. Es que mis discípulas no son débiles, porque la unión hace la fuerza; ni pocas porque representan a la mujer asturiana de todas las clases sociales» $(1905,494)$.

Llama poderosamente la atención la solemnidad y el apasionamiento con el que Mosteyrin describe la tarea que tienen por delante las mujeres españolas, sin traspasar nunca, eso sí, los muros de su casa. El tono de exaltación, el vocabulario castrense, las invocaciones a la hermandad femenina y a su fortaleza chocan bastante con la languidez, la pasividad y sobre todo con el silencio que se le presupone a ese apacible ángel del hogar que la propia Mosteyrin está defendiendo. Más que un ángel, María debió de parecerle al nutrido auditorio masculino congregado en el teatro Campoamor una aguerri-

(Sawa y Becerra 1905, 500 y 545).

33. «Yo me aflijo sólo por España. Será una debilidad; pero muy disculpable en el sexo débil» (494). Se vale aquí Mosteyrin de lo que Alison Weber definió para el caso de Santa Teresa como «retórica de la feminidad» (Navas Ocaña 2009, 124), una retórica que vamos a encontrar también en María Carbonell y a la que la propia Carmen de Burgos no es ajena. 
da amazona, dispuesta a dar la vida por el ideal. Su coraje, su arrojo en la defensa del papel tradicional de la mujer entran, y esto es lo curioso, en franca contradicción con ese mismo papel tradicional. La mujer decidida, capaz de tomar la palabra con semejante entusiasmo, estaba reclamando ser algo más que un adorno angelical, aunque en el despertar de su conciencia asuma, como lo hace María, el discurso tradicional. Mejor esto que nada, debieron de pensar ella y muchas otras. El discurso de María Mosteyrin, como los de la mayoría de las representantes de la ideología de la domesticidad, está marcado por «la complejidad, la ambigüedad y la contradicción», hallándose al mismo tiempo «dentro y fuera de la ideología dominante de género» y dejando al descubierto muchas fisuras (Blanco 2001, 27).

\section{LA IDEOLOGÍA DE LA DOMESTICIDAD Y LA ERUDICIÓN FEMENINA}

En el apartado correspondiente a las actividades llevadas a cabo en el extranjero, la Crónica publicó información sobre la participación en el centenario de una mujer de la familia real, la infanta Paz de Borbón, ya entonces princesa de Baviera por su matrimonio con el príncipe Luis Fernando. La infanta fue la encargada de la traducción de un artículo titulado «Don Quijote en Alemania» que se había publicado en el número 40 del periódico muniqués Allgemeine Zeitung, en el que se elogiaba el Quijote como «una de las obras más perfectas, en cuya lectura nos engolfamos con admiración y cuyas bellezas saboreamos con gusto». La Crónica transcribe algunos fragmentos (Sawa y Becerra 1905, 553-554). De esta traducción se realizó además una tirada de 400 ejemplares con el título S. A. R. D ${ }^{a}$ Paz de Borbón, Princesa de Baviera y el Tercer Centenario del Quijote. Don Quijote en Alemania, y uno de estos ejemplares se exhibió en la exposición bibliográfica organizada por la Biblioteca Nacional (Lucía Megías 2005, 330). Por las mismas fechas, la Revista de archivos, bibliotecas y museos publicaba bajo el marbete «Torneo en el palatinado en 1613» otra traducción de Paz de Borbón relacionada con Cervantes. En este caso se trata, como la infanta misma nos indica, de la versión al castellano de una «crónica conservada en el archivo de la Casa Real de Baviera sobre las fiestas que se celebraron con motivo del casamiento del Elector Federico V del Palatinado con Isabel Stuart, hija del rey Jacobo I de Inglaterra», en las que hubo ya un «torneo en que aparece don Quijote en caricatura como Caballero de la Triste Figura» (Borbón 1905c, 340).

Pero no cejó aquí el interés de la infanta por el Quijote porque también en 1905 publicó un volumen titulado Buscando las huellas de Don Quijote, en el que ofrece cumplida y erudita información sobre las distintas ediciones del Quijote que ha ido encontrando a lo largo de los años en las cortes europeas. Emparentada con las familias reales de toda Europa, Paz de Borbón tiene acceso a las bibliotecas públicas y privadas más importantes del momento. Pero su fuente de información principal durante el rastreo de esas «huellas» 
del Quijote en Suiza, Alemania, Austria, Francia, Italia, Grecia, Rumanía, etc. no son los bibliófilos ni los sabios de cada reino, sino las mujeres de la nobleza, con las que tiene relaciones de parentesco y que son todas tan cultas como ella. Por ejemplo en Munich, dice Paz de Borbón, «la princesa Teresa, hija del Príncipe Regente, que, por los libros científicos que ha publicado, ha sido nombrada miembro de la Academia de Ciencias de Munich, me ha proporcionado la lista de los ejemplares que se encuentran en la biblioteca del palacio real» $(1905 \mathrm{a}, 13)^{34}$.

Por otra parte, la infanta continúa en este volumen con su faceta de traductora al reproducir, trasladados al castellano, algunos fragmentos del libro de Karl Frenzel Dichter und Frauer (1866) -Poetas y mujeres, así lo cita Paz de Borbón-, en concreto aquellos que se refieren a Shakespeare y Cervantes. Según Frenzel, mientras que «la manera de ver de Shakespeare es trágica, lúgubre» (1905a, 21), Cervantes «niega la importancia y la culpa del hecho», porque «en la fe católica da la Iglesia medios para expiar cada pecado; mujeres que rompieron sus votos toman arrepentidas el velo, como Camila y Leonor; hombres que se olvidaron, vuelven, atraídos por la imagen de la Virgen, como por un magnetismo, a sus primeros amores, como Fernando a Dorotea» $(1905 b, 22)$. Pues bien, a propósito del libro de Frenzel, y en particular de la comparación entre Shakespeare y Cervantes, Paz de Borbón menciona a la reina Isabel de Rumanía, una mujer muy instruida, que cultivó no solo la traducción, sino también la poesía, la narrativa y el teatro, y que firmaba con el seudónimo de Carmen Sylva para separar su carrera literaria de su papel público (Fratricelli 2015):

La misma comparación entre Cervantes y Shakespeare me había hecho con
otras palabras estos días en una carta la reina de Rumania (Carmen Sylva).
Me llama la atención sobre un artículo admirable que Tolstoi escribió hace
algún tiempo y en el cual cuenta que Shakespeare y Cervantes murieron el
mismo año, y que en un mismo año también escribieron «Hamlet»y «Don
Quijote»; y con esa riqueza de expresión propia de la inteligencia de Car-
men Sylva, añade: «¿No es curioso? ¡La duda encarnada y la ilusión en-
carnada, producidas por los dos inmensos genios del mundo en un mismo
año!» (Borbón 1905a, 22-23).

En el ensayo ¿Qué es el arte? (1898), Tolstoi se refirió al Quijote, por su «contenido interno», como uno de los exponentes del «arte universal, que transmite los sentimientos más sencillos y cotidianos, accesibles a todo el mundo» (2007, 167-168), y además en la novela Resurrección asumió la herencia cervantina presentando a dos personajes protagonistas que son un

34. Podríamos citar otros muchos casos similares. Valga lo que dice en relación con Grecia: «Para saber lo que en Grecia habían hecho con Don Quijote, me serví de mi prima Teresa, y fue lo mejor que pude hacer, porque sin ella, que habla once lenguas a la perfección y sirve de intérprete para todo, no habría podido averiguar la hospitalidad que los griegos han dispensado a Don Quijote» (1905a, 27). 
remedo de don Quijote y Dulcinea (Bagno 1994, 90). Pero es Iván Turgueniev quien, en una conferencia pronunciada en 1860, analiza desde una perspectiva comparatista los personajes de Hamlet y don Quijote (Turgueniev 1860; Navas Ocaña 2008, 57-59) ${ }^{35}$. Sea como fuere, lo cierto es que Carmen Sylva es la principal fuente de información sobre el Quijote en Rumanía:

Naturalmente, al ir preguntando de puerta en puerta si habían visto pasar a mi Don Quijote, me había detenido en la de Carmen Sylva; presentía que los dos eran amigos. «Lo adoro», me contestó, «siento afinidades enormes con este noble defensor de grandes y bellas ideas anticuadas, en un tiempo en que ya no está en moda el sacrificarse por causas nobles, aunque se viesen en un cristal de aumento. Las mujeres han trabajado mucho para destruir esa leyenda encantadora; ¡ han querido probar tanto sus fuerzas, que ya no encuentran defensores!» Y añade, haciéndome sonreír, esta observación que no se me había ocurrido a mí: «Son verdaderamente poco atractivas, a fuerza de querer probar demasiado. Yo estoy fuera de moda, me gusta la mujer en su casa. Si Cervantes volviera ahora, tendría que hacer casi lo contrario de lo que hizo en su obra imperecedera» (Borbón 1905a, 23-24).

Sorprenden estas declaraciones de la reina de Rumanía porque ella, como escritora que fue durante toda su vida, no es que encaje demasiado en el tópico modelo del ángel del hogar, de la mujer de su casa, como tampoco encaja la infanta Paz de Borbón, que sin embargo reproduce y asume, al parecer sin vacilar, las opiniones de su amiga. Ahora bien, creo que esto no es sino una estratagema más, de las muchas que han utilizado las mujeres a lo largo de la historia para rebelarse contra los límites que les ha venido imponiendo la sociedad patriarcal, como lo fue la «retórica de la feminidad» de Santa Teresa por ejemplo, y como lo fueron, siguiendo la estela de la santa de Ávila, las constantes alusiones de las escritoras a la debilidad de su sexo (Navas Ocaña 2009). No debió de ocurrírseles otra forma mejor de que su pasión por las letras, por el saber, por la literatura, pasara desapercibida y no fuera motivo de enojo para los varones con quienes convivían, que asumir públicamente el discurso tradicional sobre la mujer y aceptar, al menos de cara a la galería, las convenciones $\operatorname{sociales}^{36}$. Esto es lo que, en mi opinión,

35. Turgueniev empieza señalando la coincidencia en la fecha de publicación de Hamlet y del Quijote: «La primera edición de la tragedia de Shakespeare Hamlet y la primera parte del Quijote aparecieron el mismo año, en los albores del siglo XVII» $(1860,67)$. Y un poco más adelante alude a la coincidencia también en la fecha del fallecimiento de Shakespeare y Cervantes: «Nuestra imaginación evoca gustosa las personalidades de estos dos poetas coetáneos que hasta murieron el mismo día» $(1860,102)$.

36. Denise Dupont ha estudiado el caso de Blanca de los Ríos como exponente de lo que llama el ángel de archivo: una mujer estudiosa que mantiene sin embargo algunos de los atributos de la ideología de la domesticidad (la sencillez, la timidez, la bondad, etc.) (Dupont 2010, 225). Aun con ciertas diferencias, creo que en esta definición de ángel de archivo caben también las figuras de la infanta Paz de Borbón y de la reina Isabel de Rumanía, mujeres doctas que no renuncian a su condición de ángeles del hogar, al contrario, que la exhiben, pero, en mi opinión, con el único fin de que les permitan seguir ejerciendo como tales mujeres doctas. 
hacen estas dos princesas ilustradas, amantes de la literatura, cuya relevancia pública no les permitía -a ellas quizás menos aún que a las demás por ser precisamente quieres eran- salirse del guion.

\title{
8. El QuiJote, LaS NOVElas de CABallerías y La EDUCACión DE LAS MUJERES
}

Si las contribuciones al centenario de Carmen de Burgos, María Mosteyrin y Paz de Borbón se incluyeron en la Crónica de Sawa y Becerra, no corrieron igual suerte las de Pilar Jiménez y Carmen García de Castro. Sin embargo, fueron editadas de manera independiente y afortunadamente tenemos acceso a ellas. Puesto que las dos son maestras -Pilar enseña en la Normal de Granada y Carmen se está formando para serlo en la Normal de Málaga-, se muestran especialmente interesadas por los valores didácticos del Quijote y, en particular, por la enseñanza moral que pueden obtener las mujeres de la lectura de la novela cervantina.

Pilar Jiménez, para quien el verdadero quijotismo consiste en ser capaces de enfrentar cualquier peligro antes que «abandonar la senda recta del honor y la virtud» $(1905,10)$, exhorta a sus discípulas a defender el bien como auténticos Quijotes, y lo que es más importante, las anima a responder solo ante el tribunal de su propia conciencia. Esto, sin ser en absoluto un planteamiento revolucionario, sí constituye en mi opinión un cierto estímulo a la independencia femenina, aunque lo es, claro está, en un discurso impregnado de los principios de la moral tradicional que apelan a la virtud y a la honra. Pero obsérvese que Pilar Jiménez anima a las jóvenes a identificarse con don Quijote, no con Dulcinea, es decir, que da por hecho que no son, o que no han de ser, simples objetos pasivos de la admiración masculina sino sujetos con conciencia de sí, cuya virtud depende de ellas mismas:

\begin{abstract}
No temáis pues que os llamen Quijotes; los que con este calificativo os motejen serán Sanchos Panzas. Amad el bien y defendedlo siempre a toda costa que por mucho que os cueste, aunque os cueste la vida y la dicha, vale mucho más. Temed tan solo faltar en algo, aunque nadie lo supiera, al respeto que cada una se debe a sí misma, pues del mundo entero podéis aislaros si os mortifica; pero de vuestra propia conciencia no podéis huir $(1905,12)$.
\end{abstract}

En el sumario de El Quijote en la escuela, Carmen García de Castro incluye un apartado que evidencia, como en el caso de Pilar Jiménez, el interés por el valor didáctico de la novela. Lo titula «Enseñanzas deducidas de las causas que produjeron la locura en don Quijote; aplicación a las modernas corrientes pedagógicas y a la educación de la mujer». El planteamiento de García de Castro es muy interesante porque compara los desastrosos resultados que en don Quijote tuvo la lectura de las novelas de caballerías con los 
que considera efectos perniciosos de la lectura de novelas en las mujeres. García de Castro retoma las tesis de Vicente de los Ríos (1780), que en la Crónica del centenario reproduce el discurso de Segundo Moreno Barcia, pero lo hace, como veremos enseguida, no para recluir a las mujeres en el hogar, no para quejarse de que los libros de caballerías animaban a las doncellas a perder su virtud, no para afirmar que Cervantes escribió el Quijote con el único fin de advertir a las mujeres de las dañinas enseñanzas que se derivaban de ellos, que fue la tesis sostenida por sus predecesores, empezando por Vicente de los Ríos y terminando en Moreno Barcia; al contrario, García de Castro se vale de esta idea, muy apreciada por el cervantismo, pero para expresar su disgusto con la clase de educación que reciben las mujeres:

... En efecto: en el Quijote se observan los funestos resultados de un exceso de trabajo imaginativo, junto a la carencia de toda otra ocupación orgánica y aún intelectual. O lo que es lo mismo: En el ingenioso hidalgo se nos presenta un ejemplo de exclusivismo, no solo mental, sino imaginativo. Esta observación es aplicable a la educación humana, y muy especialmente a la educación de la mujer.

Recluida en el estrecho recinto del hogar, entre las ocupaciones domésticas, que poco o ningún pasto pueden dar a su imaginación, la mujer, cuando es inteligente, busca algo en que saciar su anhelo de trabajo intelectual. La avidez de los estudios serios, que nadie se cuida de hacer accesibles a su entendimiento, atrofiado por siglos y siglos de quietud, le hace rechazar lo que no sea fácilmente comprensible, y busca, en cambio, lo que le proporcione agradable entretenimiento y emociones intensas. ¿Dónde encuentra los medios necesarios para esto? En las novelas.

Hay un gran número de libros cuya lectura obra en las cabezas femeninas igual efecto que los de caballerías en la de D. Quijote. Libros románticos, inverosímiles, absurdos, que estragan el gusto y pervierten el alma, causando males de todo género en el ser moral, intelectual y estético. Urge quitar de las manos de la mujer esas funestas lecturas (1906, 32-33).

Si en efecto Cervantes pretendió advertir a las mujeres de los peligros que para su virtud conllevaba la lectura de novelas de caballerías, como afirmaban Vicente de los Ríos y Moreno Barcia, precisamente una mujer de las advertidas, Carmen García de Castro, es capaz de hacer un inteligente uso de este postulado para expresar bien a las claras la insatisfacción que muchas como ella debían sentir por lo deficitario de su educación, y lo que es más importante, para rechazar con rotundidad aquello que Ríos y Barcia pretendían promover: la reclusión de las mujeres en el hogar. Las novelas de caballerías son perjudiciales desde el punto de vista moral para las mujeres, sí, viene a decir García de Castro, pero la solución no es encerrarlas entre cuatro paredes sin nada que hacer. El remedio es la educación, lo que ella llama «los estudios serios», los únicos que conseguirán enmendar el intelecto femenino «atrofiado» durante siglos por falta de instrucción.

Por lo demás, Carmen García de Castro comienza su disertación haciendo un inteligente empleo de la captatio benevolentiae mediante el recurso a la 
humildad, pero con la singularidad de que no está proclamando la debilidad de su sexo sino pidiendo excusas por no ser lo suficientemente sabia como requeriría la ocasión; y además para solventar este escollo se encomienda al ejemplo de otra mujer sabia, la alemana Roswita, estableciendo así una genealogía femenina para sus esfuerzos:

Hoy nos llaman a emitir nuestra opinión sobre el divino modelo de las letras patrias. [...] Yo acudo al llamamiento, sin ser sabia ni poetisa, pero acudo "con el asiduo martillo de la voluntad", con el cual pretendo, como Roswita, la humilde artista medieval, entonar algunos sones en loor del genio» $(1906,8)$.

\section{El Feminismo de Cervantes}

Otra maestra, María Carbonell ${ }^{37}$, pronunció el 7 de mayo de 1905 en la Institución para la Enseñanza de la Mujer de Valencia el discurso Las mujeres del Quijote. Carbonell comienza justificando el tema de su conferencia teniendo en cuenta el lugar en el que va a ser pronunciada: un centro de educación femenina. Esta circunstancia ha sido la que la ha animado a tomar la decisión de disertar sobre las mujeres del Quijote. Por otra parte, el tópico de un Cervantes indulgente y caballeroso con las mujeres, del que ya hemos hablado a propósito de Carmen de Burgos, hace acto de presencia al principio de la intervención de María Carbonell:

El gran Cervantes, al retratar a las mujeres puso de manifiesto su caballerosidad e hidalguía nativas, su exquisito sentimiento y la bondad de su corazón. Jamás se ensañó con ellas, como Quevedo y otros escritores, ni sacó a la pública vergüenza sus defectos y debilidades, comprendiendo que unos y otras son propios de la humanidad y no exclusivamente del sexo femenino $(1905,4)$.

María Carbonell no duda en afirmar que «En el Quijote nos ofrece Cervantes una galería completa de mujeres todas adorables y algunas con cualidades dignas de loa y alabanza» $(1905,4)$. Para refrendar esta idea acude en primer lugar a la figura de Dulcinea, en quien Cervantes encarnó no solo «la belleza supra-sensible», sino ante todo el amor «platónico», «eterno, inmaculado y puro», espiritual $(1905,5)$. María Carbonell no escatima esfuerzos en demostrar el alto concepto en que Cervantes parece tener a las mujeres: «El protagonista de la obra de Cervantes creyó a la mujer capaz de constancia, fidelidad, pureza, honestidad, desinterés y abnegación» $(1905,5)$. Sin embargo, María puntualiza que «los que presentan en la actualidad tipos femeninos,

37. Como ya he indicado, a María Carbonell, tras su jubilación, la sustituiría en la cátedra de Valencia precisamente la almeriense Carmen García de Castro. 
amparándose del realismo, las retratan impresionables, volubles, ignorantes, tornadizas, vanidosas, inconstantes y positivas» $(1905,5)$. Y con criterio muy certero apunta: «Callan sus virtudes y ponen de relieve sus defectos, las adulan en presencia y las ultrajan en ausencia» $(1905,5)$.

Carbonell convierte a hombres y mujeres en nuevos Quijotes, que deben luchar por su ideal, ya sea este ideal la patria, la perfección o la belleza: «Seamos Quijotes, pero siempre enamorados de Dulcinea, esto es, del ideal en cualquiera de sus formas y manifestaciones: el ideal de la Patria, el de la perfección, el de la belleza» $(1905,6)$. Les recomienda además a sus discípulas que tengan en gran estima el amor platónico, cuyo principal exponente ha sido Gustavo Adolfo Bécquer con el célebre «Poesía eres tú», del que ella se hace eco, sin nombrarlo directamente, cuando dice: «Y vosotras, jóvenes que me escucháis, no desdeñéis en absoluto el amor platónico personificado en Dulcinea, porque es la encarnación de la poesía y poesía y mujer deben ser dos cosas muy parecidas» $(1905,6)$. Por supuesto se han de identificar con el ángel del hogar, el principal prototipo femenino del momento: «La prosa de la vida necesita un contrapeso, y vosotras las reinas del hogar, tenéis el deber de poetizarlo» $(1905,6)^{38}$.

Sin embargo, a pesar de estas concesiones a los modelos femeninos tradicionales imperantes en la época, que colocan a la mujer en el hogar o la convierten en un ser ideal, María Carbonell se va a embarcar a partir de aquí en una entusiasta defensa del personaje de Marcela, la pastora esquiva, evidenciando, y esto es muy importante, la opinión tan distinta que sobre ella tienen hombres y mujeres:

Otra de las simpáticas mujeres del Quijote es la pastora Marcela. Ingrata, cruel, desamorada, fría, desdeñosa, dura de corazón, falta de sentimientos, fiera y ruda al decir de sus desdeñados amadores, que con el insano egoísmo de la fuerza y la superioridad, pretendían hallar correspondencia. Si las mujeres tuviéramos que retratarla diríamos que Marcela era hermosa y discreta, digna en el porte, valerosa en el resistir, prudente en el rechazar, altiva, enérgica con los que se desmandaban, firme en sus convicciones, amante de su libertad, incapaz de rendirse sin amor, en una palabra, todo un carácter entero, resuelto, convencido (1905, 6-7).

Marcela aparece así como un modelo femenino de prudencia, discreción, valor, firmeza y, sobre todo, libertad, modelo que Carbonell pretende inculcar a sus discípulas. Además, hace suyas las quejas de Sor Juana Inés de la Cruz sobre la inconstancia de los hombres y cita muy a propósito sus célebres redondillas:

La presunción masculina agota el repertorio de las burlas para calificar a las mujeres de crédulas, complacientes y fáciles de conquistar, y trata de

38. Según Begoña Sáez, María Carbonell se mueve dentro de los parámetros del «discurso de la domesticidad que evoca el modelo femenino de la perfecta casada» $(2006,32)$. 
crueles, de insensibles y hasta de incompletas a las que no ponen empeño en atraer y muestran amor a su independencia o aficiones que las desvían del flirteo, la coquetería y las aventuras galantes. Semejante a coto de abundante caza quiere el hombre al sexo femenino. En donde pueda entrar y cobrar piezas sin gran fatiga, aunque después de verlas a sus pies como a despojo no las aprecia y ponga su pensamiento en las pocas que lograron escapar. Ya lo decía Sor Juana Inés de la Cruz en una de sus célebres redondillas:

Pues como ha de estar templada

La que nuestro amor pretende,

Si la que es esquiva ofende

Y la que es fácil enfada? $(1905,7)$

Por otra parte, María Carbonell aprovecha la oportunidad que le brinda Marcela para hacer un llamamiento contra la violencia que sufren muchas mujeres: «Pero las pobres Marcelas de nuestra época pagan frecuentemente con la vida sus esquiveces. Los crímenes pasionales que tanto abundan al presente, no suelen tener otro origen sino el deseo de lograr por la fuerza lo que de grado no se rinde» $(1905,7)$.

Esta encendida defensa de Marcela contrasta con la tradición interpretativa sobre el personaje, tradición que no es por cierto muy positiva, siendo Marcela, de entre todas las mujeres cervantinas, quien más críticas adversas concita, fundamentalmente por su desenvoltura, su excesiva liberalidad, y sobre todo porque con su soltería y su virginidad, que defiende a capa y espada, encaja mal en el prototipo del ángel del hogar (Navas Ocaña 2008, 61-74). El III Centenario será ocasión de renovadas críticas a Marcela en la pluma de nombres tan célebres como el de José Ortega y Gasset (Navas Ocaña 2018).

En cambio, María Carbonell, una mujer ya madura -tiene en 1905 cincuenta y tres años-, con una amplia trayectoria como docente que se inicia en 1871, no duda en acogerse al abrigo de la protectora sombra de Marcela para justificar el afán de independencia que mujeres como ella pretenden cultivar, manifestando su desagrado por los devaneos amorosos que hasta entonces han constituido lo esencial de la vida femenina. Otras maestras también emitieron juicios positivos sobre Marcela. Es el caso de Carmen García de Castro y de Pilar Jiménez, pero ninguna de las dos entra tan de lleno en el análisis del personaje como lo ha hecho María Carbonell. Ambas destacan, no obstante, la discreción y el vigor de las razones aducidas por Marcela ${ }^{39}$.

Carbonell repasa a continuación, y ya brevemente, los distintos personajes femeninos del Quijote llegando a la conclusión siguiente:

39. Pilar Jiménez considera un «dechado de argumentación vigorosa los discretos razonamientos de Marcela» $(1905,8)$; y Carmen García de Castro menciona entre los «pasajes de grave y profunda tristeza» en el Quijote, «las discretas razones de Marcela» $(1906,12)$. 
¡Cuánta psicología femenina, qué tesoros de observación, qué riqueza de análisis, qué conocimiento tan profundo del corazón de la mujer encierra la gran obra de Cervantes! En el Quijote se revela como gran moralista, sociólogo, feminista, jurisconsulto, médico, teólogo, hablista $(1905,11)$.

Carbonell proclama a Cervantes feminista en un párrafo en el que la palabra aparece amortiguada por otras que se refieren al escritor como un dechado de cualidades y un sabio en infinidad de materias, al estilo del mismísimo Homero. Es la primera vez que se le atribuye a Cervantes el adjetivo feminista ${ }^{40}$ y Carbonell tiene buen cuidado de emplearlo junto a otros, todos muy positivos, que hacen del alcalaíno un precursor en ámbitos diversos: la moral, la teología, el derecho, etc. ${ }^{41}$

\section{El otro Centenario}

El Centenario del Quijote en 1905 fue efectivamente la efemérides que vino a aglutinar y a canalizar las ansias de regeneración nacional tras el desastre del 98, pero lo que hasta ahora no se ha señalado, ni se le ha dado la importancia que, en mi opinión, merece, es que algunas intelectuales españolas reinterpretaron en clave feminista los símbolos nacionales de esa regeneración, es decir, convirtieron a don Quijote y a Dulcinea en la divisa de sus reivindicaciones, los erigieron en los santos patronos de sus anhelos de cambio, aunque lo hicieran de una manera que hoy nos parece tímida, pero que hay que valorar en el contexto en el que se produce, un contexto ciertamente poco favorable a nada que no sea el hogar, el matrimonio y la maternidad. De

40. Lo hemos encontrado también en el discurso que el abogado Matías Peñalba Alonso de Ojeda pronuncia en el teatro de la ciudad de Palencia el 8 de mayo de 1905, y que sí recoge la Crónica $(1905,495-498)$.

41. Pardo Bazán y Carmen de Burgos también subrayarán e incluso parodiarán esta consideración de Cervantes como precursor en muy diversos ámbitos de la cultura y de la ciencia, algo que era muy común en la época. Pardo Bazán, por ejemplo, vio en un raro personaje de Persiles y Segismunda el anticipo de algunas formas de periodismo contemporáneo. Se trata del peregrino con el que Auristela y Periandro se topan en un mesón próximo a Roma, quien solicitaba a todo aquel que encontraba en su camino que incluyera un dicho, una «sentencia aguda», en un cartapacio que llevaba siempre consigo a tal efecto, con el fin de, una vez completadas sus páginas, poder publicar un volumen con todos los aforismos atesorados. No sin ironía doña Emilia nombra al tal peregrino como antecesor de «los jóvenes repórteres a quienes el director encarga de sacar unas líneas a D. Fulano o a D. Zutano» y concluye que se ha de reconocer «en el hecho de que el gran Manco haya precedido a tantos cazadores de prosa y versos y a tan marcadas tendencias y formas de la vida intelectual de nuestros días, la cualidad de genio, que se adelanta en todo, hasta en lo que la multitud, más tarde, recoge, adopta y practica, sin sospechar de dónde ha salido, ni la mente fantástica e inventiva en que nació» (1905e, 5). En este sentido, enlaza con un texto posterior de Carmen de Burgos, titulado «La Gloria. Diálogo entre Cervantes y un periodista», publicado en la colección de diálogos La voz de los muertos (1911), en el que Carmen de Burgos pone en boca de Cervantes la siguiente queja: «iQué profanación! Todos en mí pusisteis vuestras manos. Ya ni yo mismo conozco eso que llamáis mi obra maestra; tal habéis sutilizado atribuyéndome intenciones de cosas que ni siquiera pensé...» (1911, 98). Emilia Pardo Bazán y Carmen de Burgos se distancian con estas parodias una vez más del cervantismo oficial. 
hecho, no faltaron voces autorizadas, como la del académico Juan Cavestany, que les recordó - muy galantemente, eso sí- que su único cometido en la magna empresa de la regeneración nacional era apoyar a sus maridos.

Difícil fue, por tanto, para ellas superar los límites que les imponía la moral de la época y lo hicieron sufriendo muchas contradicciones. Ninguna se enfrenta abiertamente al modelo femenino del ángel del hogar. Al contrario, ya hemos visto cómo Carmen de Burgos y María Carbonell tienen buen cuidado de mencionarlo en discursos que, sin embargo, denuncian la deplorable situación en la que se encuentran las mujeres españolas: Carmen de Burgos se queja de la falta de educación y de protección legal, y Carbonell se atreve a hablar abiertamente de malos tratos. Y lo que es más curioso, aquellas que sí asumen decididamente la ideología de la domesticidad, como María Mosteyrin Morales, lo hacen con tales bríos, lo expresan con tal convicción, que más que ángeles parecen amazonas, y su discurso firme, resuelto, poco tiene que ver con la sumisión y la pasividad que se le presupone a ese ángel del hogar.

Otro tanto podemos decir de Paz de Borbón y de Carmen Sylva, cuyos alegatos en defensa del modelo femenino tradicional resultan poco convincentes a tenor de su tenaz dedicación a la literatura. Buscando las huellas de Don Quijote de Paz de Borbón es una de las primeras muestras del cervantismo femenino y, como tal, marca un hito muy importante en los estudios sobre Cervantes. Además, el hecho de que Paz de Borbón se congratule del grado de erudición que atesoran muchas mujeres de la nobleza europea, que son las que le proporcionan información sobre la suerte del Quijote en sus respectivos países, evidencia la existencia ya en este momento de redes de mujeres eruditas, todas políglotas, como Paz se encarga de subrayar a cada momento, con intereses que van mucho más allá de la aguja y el bastidor. En definitiva, la imagen femenina que la infanta ofrece aquí no es en absoluto la tradicional, por más que en algunas ocasiones haga guiños al omnipresente ángel del hogar.

Y si con Paz de Borbón y sus sabias amigas vislumbramos lo que podríamos considerar primigenios cenáculos de erudición femenina en torno a Cervantes, las Escuelas Normales de Maestras van a ser también una importante cantera de mujeres cervantistas, de la que saldrán nombres tan notables como los de María Carbonell y Carmen García de Castro, cuya aportación ya hemos puesto aquí en valor. No olvidemos que Carbonell es la primera que proclama el feminismo de Cervantes y la primera que rompe una lanza decidida por el personaje de Marcela, y que Carmen García de Castro reinterpreta a la luz de las nuevas reivindicaciones feministas sobre el derecho a la educación la lectura tradicional del Quijote como sátira de los libros de caballerías. Hemos visto además cómo Concepción Sainz de Otero propicia la publicación del erudito trabajo de su discípula María del Rosario Garrido sobre los libros de caballerías y cómo Carmen García de Castro le dedica a su maestra, a Suceso Luengo, El Quijote en la escuela. El magisterio femenino es, por tanto, ya un hecho que la celebración del III Centenario en las 
Escuelas Normales pone sobre la mesa. A la mujer mantenida la va a sustituir una nueva profesional, que se gana la vida con su trabajo de maestra y que les inculca a sus alumnas el amor al estudio, la devoción por los libros, por el saber.

En suma, redes de mujeres sabias, que ejercen el magisterio sobre otras, vínculos entre mujeres que son fruto ante todo del afán de conocimiento: esto es lo que trajo consigo ese otro Centenario, que quedó ciertamente ensombrecido por las alharacas del oficial, pero que ahí sigue, más de cien años después, ofreciendo una lección de tenacidad y de sabiduría. Que doña Emilia Pardo Bazán expresara tan a las claras su disconformidad con esos fastos oficiales y que se mostrara muy crítica, hasta el punto de llegar a la parodia, con algunos de los tópicos del cervantismo de la época, como la absurda creencia de que Cervantes era un experto en multitud de disciplinas, no viene sino a corroborar la idea de que, desde los márgenes, se estaba gestando un discurso diferente sobre el Quijote, un discurso que dio voz a las esperanzas de cambio de las mujeres.

Hubo, en efecto, otro Centenario, el que aventura doña Emilia con sus quejas sobre la precipitación y mala organización del oficial, con su propuesta de actividades alternativas, con su exaltación de los actos organizados por la duquesa de Villahermosa y la convicción de que si las mujeres contaran con medios económicos planearían las cosas de otra manera. Hubo, en efecto, otro Centenario, el que protagonizaron las maestras, muy interesadas en los valores educativos del Quijote, que utilizan para defender la educación femenina. Hubo, en efecto, otro Centenario, encabezado por Carmen de Burgos, que preconizó la resurrección del galante don Quijote con el fin de que pudiera nacer una nueva Dulcinea. Hubo, en efecto, otro Centenario, el de María Carbonell, que hace de Cervantes, del genio por excelencia de las letras españolas, un feminista.

\section{BIBLIOGRAFÍA CITADA}

Agulló Díaz, M. ${ }^{a}$ del Carmen. 2001. «Expediente instruido por la Universidad de Valencia en 1929 a la profesora de la Normal de Valencia D. ${ }^{a}$ Carmen García de Castro, debido a la acusación de "difundir entre sus alumnas doctrinas perniciosas"». Historia de la educación 20: 467-482.

Agulló Díaz, M. ${ }^{\mathrm{a}}$ del Carmen y Juan Manuel Fernández-Soria. 2014. «La depuración franquista del profesorado de las Escuelas Normales de Alicante, Castellón y Valencia». Revista de Educación 364, abril-junio: 197-221.

Armiñán, Luis de. 1905. «En honor de Cervantes». Unión Ibero-Americana XIX, n. ${ }^{\circ}$ extra de 16 de junio: 54-55.

Bacardí, Montserrat e Inma Estany, eds. 2006. El Quixot en català. Montserrat: Publicacions de l'Abadia de Montserrat.

Badillo Baena, Rosa M. 1992. Feminismo y educación en Málaga: el pensamiento de Suceso Luengo de la Figuera (1898-1920). Málaga: Servicio de Publicaciones y Divulgación Científica de la Universidad de Málaga. 
Bagno, Vsevolod. 1994. El Quijote vivido por los rusos. Madrid: Consejo Superior de Investigaciones Científicas y Diputación de Ciudad Real.

Ballarín, Pilar. 1996. «Dulce, buena, cariñosa... en torno al modelo de maestra/madre del siglo XIX». En El modelo femenino. ¿Una alternativa al modelo patriarcal?, eds. Inés María Calero Secall y M. ${ }^{a}$ Dolores Fernández de la Torre Madueño, 69-88. Málaga: Universidad de Málaga.

Blanco, Alda. 2001. Escritoras virtuosas: narradoras de la domesticidad en España. Granada: Universidad de Granada.

Borbón, Paz de. 1905a. Buscando las huellas de Don Quijote. Friburgo de Brisgovia: B. Herder.

Borbón, Paz de. 1905b. S. A. R. D a Paz de Borbón, Princesa de Baviera y el Tercer Centenario del Quijote. Don Quijote en Alemania. Madrid: Litografía Mateu. Facsímil en Cuenca: Diputación Provincial de Cuenca, 2005.

Borbón, Paz de. 1905c. «Torneo en el palatinado en 1613». Revista de archivos, bibliotecas y museos IX, 5 de mayo de 1905: 340-344.

Burgos, Carmen de. 1905. «La resurrección de Don Quijote». Unión Ibero-Americana, año XIX, n. ${ }^{\circ}$ extra de 16 de junio de 1905: 62. Incluido en Crónica del Centenario de Don Quijote, dirs. Miguel Sawa y Pablo Becerra. Madrid: Establecimiento Tipográfico de Antonio Marzo: 275-276.

Burgos, Carmen de. 1911. «La Gloria. Diálogo entre Cervantes y un periodista». En La voz de los muertos, 97-103. Valencia: F. Sempere y Compañía.

Camarero Rioja, Fernando. 2013. «Teoría y práctica del cine educativo en España (18951923)». Cahiers de civilisation espagnole contemporaine 11. Accesible en: $<\mathrm{http} / /$ journals.openedition.org/ccec/4843>. Fecha de acceso: 3 de marzo de 2020.

Carbonell, María. 1905. Las mujeres del Quijote. Valencia: Imprenta de Doménech y Taroncher.

Carbonell, María. 2006. Las mujeres del Quijote y otros escritos, ed. Begoña Sáez Martínez. Valencia: Institución Alfonso el Magnánimo.

Castells, Ricardo. 2016. «María Carbonell Sánchez y los comienzos de los estudios femeninos de Cervantes: las mujeres escritoras, las Escuelas Normales y el tercer centenario de Don Quijote (1905)». Bulletin of the Cervantes Society of America 36 (1): 67- 84.

Cavestany, Juan Antonio. 1905. «Discurso pronunciado por el Excmo. Sr. D. Juan Antonio Cavestany». En Crónica del Centenario de Don Quijote, eds. Miguel Sawa y Pablo Becerra, 322-330. Madrid: Establecimiento Tipográfico de Antonio Marzo.

Cervantes, Miguel de. 1798-1800. El Ingenioso Hidalgo Don Quixote de la Mancha, ed. Juan Antonio Pellicer. Madrid: Gabriel de Sancha.

Dupont, Denise. 2010. «Blanca de los Ríos, Emilia Pardo Bazán, Francisca Larrea y Cecilia Böhl de Faber: hijas, madres, y la creación de un modelo de mujer estudiosa, o “ángel de archivo"». Siglo XIX (Literatura Hispánica) 16, monográfico sobre «Escritoras decimonónicas en singular»: 219-240.

«En honor de Cervantes». 1905. La Época 19.716, año LVII, 15 de mayo: 5.

Ezama Gil, Ángeles. 2013. «Las conferencias como método pedagógico. Las mujeres conferenciantes en la Unión Ibero-Americana y el Centro Ibero-Americano de Cultura Popular Femenina». Boletín de la Institución Libre de Enseñanza II, 91/92: 125-150.

Ezama Gil, Ángeles. 2015. La educación de la mujer a comienzos del siglo XX: el Centro Iberoamericano de Cultura Popular Femenina (1906-1926). Málaga: Servicio de Publicaciones de la Universidad de Málaga.

Fernández Rubio, Carmen. 1997. La Escuela Normal Masculina de Oviedo y su incidencia en la formación de maestros (1900-1940). Oviedo: Servicio de Publicaciones de la Universidad de Oviedo. 
Fratriccelli, Bárbara. 2015. «Las biografías de Carmen Sylva, la reina escritora de Rumanía». En Aproximació a l'altre: biografies, semblances i retrats, coords. Enric Balaguer Pascual, M. Jesús Francés Mira y Vincent Vidal Lloret, 141-147. Ámsterdam: John Benjamin Publishing.

Frenzel, Karl. 1866. Dichter und Frauen. Hannover: Carl Rümpler.

García de Castro, Carmen. 1906. El Quijote en la escuela. Desarrollo del tema: enseñanzas literarias y pedagógicas contenidas en el Quijote [premiado en el Certamen que con motivo del Tercer Centenario de la publicación de El Ingenioso Hidalgo Don Quixote de la Mancha se celebró en Málaga por los centros docentes en mayo de 1905]. Écija: Imprenta Reyes, Mas y Prat.

García Sánchez, Jesús, ed. 2005. Visiones del Quijote desde la crisis española de fin de siglo, pról. Luis Alberto de Cuenca. Madrid: Visor.

Garrido, María del Rosario. 1905. «Libros de caballería». En La Escuela Moderna. Revista pedagógica y administrativa de Primera y Segunda Enseñanza 170, año XV: 342348.

Grau-Llevería, Elena. 2004. «Ironía, parodia e inversión en La muñeca, de Carmela Eulate Sanjurjo». Crítica Hispánica 26 (1-2): 75-94.

Jiménez, Pilar. 1905. Cervantes y el Quijotismo. Discurso pronunciado por la Srta. Pilar Jiménez en la velada con que la Escuela Normal de Maestras de Granada festejó el III Centenario de la aparición del Quijote. Granada: Tipografía de López Guevara.

López Navia, Santiago. 2005. Inspiración y pretexto. Estudios sobre las recreaciones del Quijote. Madrid: Iberoamericana Vervuert.

Lucía Megías, José Manuel. 2005. «Torneo en el palatinado en 1613, por Paz de Borbón». Anales Cervantinos 37: 329-334. https://doi.org/10.3989/anacervantinos.2005.

Marín Eced, Teresa. 1990. La renovación pedagógica en España (1907-1936). Los pensionados en pedagogía por la Junta para Ampliación de Estudios. Madrid: CSIC.

Martín Murillo, María Luisa y María Jesús Fraga. 2016. «Publicaciones cervantinas de autoría femenina (1905-1916). Lectora 22: 145-164.

Menéndez y Pelayo, Marcelino. 1905. «Cultura literaria de Miguel de Cervantes y elaboración del Quijote». En Crónica del Centenario de Don Quijote, eds. Miguel Sawa y Pablo Becerra, 137-156. Madrid: Establecimiento Tipográfico de Antonio Marzo.

Morales Zeno, Ana. 1995. «La otra cara de la historia: los ensayos de Carmela Eulate Sanjurjo». Revista de Estudios Hispánicos 22: 379-396.

Morán, Francisco. 1905. «Naturaleza y objeto del Quijote». En Crónica del Centenario de Don Quijote, eds. Miguel Sawa y Pablo Becerra, 542-548. Madrid: Establecimiento Tipográfico de Antonio Marzo.

Moreno Barcia, Segundo. 1905. «La mujer en el Quijote». En Crónica del Centenario de Don Quijote, eds. Miguel Sawa y Pablo Becerra, 415-417. Madrid: Establecimiento Tipográfico de Antonio Marzo.

Mosteyrin Morales, María. 1905. «Cómo impresiona el Quijote (datos directos)». En Crónica del Centenario de Don Quijote, eds. Miguel Sawa y Pablo Becerra, 493-494. Madrid: Establecimiento Tipográfico de Antonio Marzo.

Navarro Ledesma, Francisco. 1905. «En el Ateneo. Cómo se hizo el Quijote. Primera Conferencia. Segunda Conferencia». En Crónica del Centenario de Don Quijote, eds. Miguel Sawa y Pablo Becerra, 205-244. Madrid: Establecimiento Tipográfico de Antonio Marzo.

Navas Ocaña, Isabel. 2008. Las mujeres del Quijote y la crítica. Madrid: Editorial Fundamentos.

Navas Ocaña, Isabel. 2009. La literatura española y la crítica feminista. Madrid: Editorial Fundamentos. 
Navas Ocaña, Isabel. 2018. «Leyendo a Ortega como una mujer». Studia Neophilologica 90 (1): 126-140.

Navas Ocaña, Isabel. En prensa. «En sus brazos se ahoga todo heroísmo. La crisis del 98 y los personajes femeninos del Quijote».

Núñez Rey, Concepción. 2005. Carmen de Burgos Colombine en la Edad de Plata de la literatura española. Sevilla: Fundación José Manuel Lara.

Ortiz Alvear, Natividad. 2007. Mujeres masonas en España. Diccionario biográfico (18681939). Santa Cruz de Tenerife: Ediciones Idea.

Palau, Montserrat. 2012. «Les aportacions al feminisme de les folkloristes Maria Gràcia Bassa i Maria Baldó». En La recerca folklòrica: persones i institucions, coords. Joseph Temporal y Laura Villalba, 13-25. Alicante: Institut Alicantí de Cultura Juan GilAlbert.

Pardo Bazán, Emilia. 1905a. «La vida contemporánea». La Ilustración Artística XXIV, 1211, 13 de marzo: 170.

Pardo Bazán, Emilia. 1905b. «La vida contemporánea». La Ilustración Artística XXIV, 1217, 24 de abril: 266.

Pardo Bazán, Emilia. 1905c. «La vida contemporánea». La Ilustración Artística XXIV, 1221, 22 de mayo: 330.

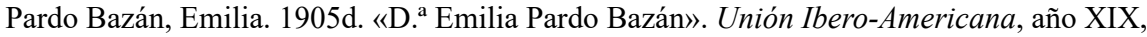
n. ${ }^{\circ}$ extra de 16 de junio: 62-64.

Pardo Bazán, Emilia. 1905e. «Cervantes, periodista a la moderna». En El Centenario del Quijote en Galicia, 5. La Coruña: Liga de Amigos de La Coruña.

Peñalba Alonso de Ojeda, Matías. 1905. «Discurso». En Crónica del Centenario de Don Quijote, eds. Miguel Sawa y Pablo Becerra, 495-498. Madrid: Establecimiento Tipográfico de Antonio Marzo.

Ramón y Cajal, Santiago. 1905. «Psicología del Quijote y el quijotismo». En Crónica del Centenario de Don Quijote, eds. Miguel Sawa y Pablo Becerra, 161-168. Madrid: Establecimiento Tipográfico de Antonio Marzo.

Riera, Carmen. 2005. El Quijote desde el nacionalismo catalán, en torno al Tercer Centenario. Barcelona. Ediciones Destino.

Ríos, Vicente de los. 1780. «Análisis del Quixote». En El Ingenioso Hidalgo Don Quijote de la Mancha, xliii-clii. Madrid: Joaquín Ibarra [facsímil en Jaén: Universidad de Jaén, 2005].

Rivera, Ángel. 1999. «Relectura de la femme fatale en el contexto de la modernidad decimonónica: la muñeca de Carmela Eulate Sanjurjo. Chasqui: Revista de Literatura Hispanoamericana 227 (2): 54-69.

Sáez, Begoña. 2006. «Introducción». En María Carbonell, Las mujeres del Quijote y otros escritos, 9-80. Valencia: Institución Alfonso el Magnánimo.

Sáiz de Otero, Concepción. 1902. «El feminismo en España». En La Escuela Moderna. XIII, n. ${ }^{\circ} 79$, octubre, 248-260 y n. ${ }^{\circ}$ 80, noviembre, 321-334. Reeditado en Roberta Johnson y Maite Zubiaurre, eds. 2012. Antología del pensamiento feminista español, 83-90. Madrid: Cátedra.

Santos Vaquero, Ángel. 2012. «Antonieta Freixa Torroja». En Educación, Ciencia y Cultura en España. Auge y colapso (1907-1940), coord. Isidro Sánchez Sánchez, 205-207. Ciudad Real: Almud Ediciones de Castilla-La Mancha y Centro de Estudios de Castilla-La Mancha (UCLM).

Sawa, Miguel y Pablo Becerra. 1905. Crónica del Centenario de Don Quijote. Madrid: Establecimiento Tipográfico de Antonio Marzo.

Scanlon, Geraldine M. 1987. «La mujer y la instrucción pública: de la ley Moyano a la II República». Historia de la Educación. Revista interuniversitaria 6: 193-208. 
Tolstoi, Lev. N. 2007. ¿Qué es el arte?, introducción Víctor Gallego Ballesteros. Pamplona: EUNSA.

Turgueniev, Iván. 1986 [1860]. «Hamlet y Don Quijote». En Cervantes, Samuel T. Coleridge, Heinrich Heine, William Hazlitt, Iván Turgueniev y Fedor Dostoievsky, 67-113. Madrid: José Esteban Editor.

Uñó, Félix. 1905. «Las mujeres del Quijote». En La Academia Calasancia XIV, 315, 18 de mayo: 412-416.

Valbuena, P. 1905. La resurrección de Don Quijote. Nuevas y jamás oídas aventuras de tan ingenioso hidalgo. Barcelona: Antonio López, editor, Librería española, edición facsímil publicada por La Tempestad, en 2005.

Valera, Juan. 1905. «Discurso del Excmo. S. D. Juan Valera». En Crónica del Centenario de Don Quijote, eds. Miguel Sawa y Pablo Becerra, 121-134. Madrid: Establecimiento Tipográfico de Antonio Marzo.

Velilla, Mercedes de. 2008. El vencedor de sí mismo. Sevilla: Nuño Editorial.

Velilla, Mercedes de. 2018. Un sueño de libertad. Poemas 1873-1918, pról. José Julio Cabanilles. Sevilla. Editorial Renacimiento.

Villahermosa, Duquesa de, ed. 1905. Album cervantino aragonés de los trabajos literarios $y$ artísticos con que se ha celebrado en Zaragoza y Pedrola el III Centenario de la edición príncipe del Quijote. Madrid: Casa de la Viuda e hijos de M. Tello, Impresor de Cámara de S. M.

Recibido: 4 de agosto de 2019

Aceptado: 1 de febrero de 2020 